\title{
WestVirginiaUniversity
}

THE RESEARCH REPOSITORY @ WVU

Graduate Theses, Dissertations, and Problem Reports

2016

\section{Somewhat familiar}

Brett Herron

Follow this and additional works at: https://researchrepository.wvu.edu/etd

\section{Recommended Citation}

Herron, Brett, "Somewhat familiar" (2016). Graduate Theses, Dissertations, and Problem Reports. 5795.

https://researchrepository.wvu.edu/etd/5795

This Thesis is protected by copyright and/or related rights. It has been brought to you by the The Research Repository @ WVU with permission from the rights-holder(s). You are free to use this Thesis in any way that is permitted by the copyright and related rights legislation that applies to your use. For other uses you must obtain permission from the rights-holder(s) directly, unless additional rights are indicated by a Creative Commons license in the record and/ or on the work itself. This Thesis has been accepted for inclusion in WVU Graduate Theses, Dissertations, and Problem Reports collection by an authorized administrator of The Research Repository @ WVU. For more information, please contact researchrepository@mail.wvu.edu. 
SOMEWHAT FAMILIAR

Brett Herron

Thesis submitted

to the College of Creative Arts

at West Virginia University

in partial fulfillment of the requirements for the degree of

Masters of Fine Arts in

Printmaking

Joseph Lupo, M.F.A., chair

Michael Sherwin, M.F.A.

Jason Lee, M.F.A.

Kofi Opoku, M.F.A.

Department of Art and Design

Morgantown, West Virginia

2016

Keywords: Installation, Photography, Relational Aesthetics, Sculpture, Spatial

Awareness

Copyright 2016 Brett Herron 


\section{Abstract \\ SOMEWHAT FAMILIAR}

Brett Herron

My MFA written thesis addresses work completed and shown in a thesis exhibition at West Virginia University as well as significant influences to my studio process. While my focus is printmaking, the work presented in the exhibition consists of several sculptural and photographic pieces. This thesis, along with the supporting exhibition, will address my investigations into extending Minimalism's anonymity and relational aesthetics while adhering to my own predetermined artistic parameters. The work is concerned with observed form and composition along with the transformation of mundane and knowable materials into uncertain sculptures that highlight their physical properties. I emphasize the material presence and spatial ambiguities of the work, while rejecting the conventions of sculpture and painting as mainstays of artistic production. 


\section{Acknowledgments}

I would like to express my special appreciation and thanks to my advising committee, Joseph Lupo, Michael Sherwin, Jason Lee, and Kofi Opoku; you have all been extremely influential in my artistic and conceptual development. A special thank you to my parents, Tom and Robin Herron as words cannot express how grateful I am for all of the sacrifices you have made on my behalf and for your continuous encouragement and support of my education. I would also like to thank my sister Kerri who has supported me and incented me to strive towards my goals. Finally, I would like to express appreciation to my beloved wife for always supporting me in my academic pursuits and for the wonderful life that we share together. 
Table of Contents

Abstract................................................................. ii

Acknowledgments......................................................... iii

Table of Contents....................................................... iv

Introduction................................................................ 1

Influences................................................................ 3

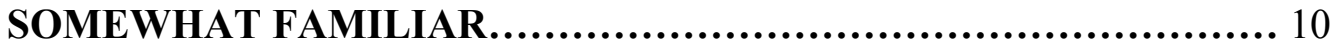

Conclusion..................................................................... 16

Illustrations............................................................ 17

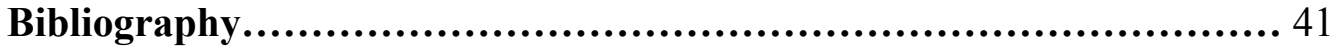

Curriculum Vitae......................................................... 44 


\section{Introduction}

All right, can we try to define art? We have tried, everybody has tried, and every century there is a new definition of art. I mean that there is no one essential that is good for all centuries. So if we accept the idea that trying not to define art is a legitimate conception, then the readymade can be seen as a sort of irony, or an attempt at showing the futility of trying to define art, because here it is, a thing that I call art. I didn't even make it myself, as we know art means to make, hand make, to make by hand. It's a hand-made product of man, and there instead of making, I take it ready-made, even though it was made in a factory. But it is not made by hand, so it is a form of denying the possibility of defining art.

Marcel Duchamp (January $19^{\text {th }}, 1959$ ) from a BBC radio broadcast

Marcel Duchamp responded in a BBC radio interview from 1959, when he was asked whether there was any way we can think of a readymade as art, "That is the very difficult point, because art first has to be defined." Duchamp argued that an ordinary object could be elevated to the dignity of a work of art by the choice of an artist.

The importance of traditional materials and methods in the fine arts to recreate familiar everyday objects questions whether exploring and highlighting the physical properties of the materials can actually stand as works of art. Color, shape, texture and surface only emphasize the formal, traditional and physical aspects of the work. No matter what form the final piece may have, it must begin with an idea; I find that my successful ideas generally have a simple appearance stemming from a basic, artistic intuition.

In this sense, I work in response to ideas and materials, including objects found on construction sites, or purchased from the hardware store. Through the process of trial and frequent error and the combination of concept and intuition, I aim to provoke a visceral reaction that investigates the physical and psychological qualities of materials. My

\footnotetext{
${ }^{1}$ Hamilton, George H. Interview with Marcel Duchamp. BBC Radio Third Programme. (New York, January 19, 1959).

${ }^{2}$ Editors, Artspace. "Book Report: The Four-Hour Art Week: Read Carol Bove's Self-Help Guide for
} 
impulse to put these everyday objects together places an emphasis on the subtle relationships that question the viewer's experience. When complete, the work relates to contemporary installation and experiential work keeping the viewer poised in a state of slight unease, making one highly aware of their own physicality within the space and forcing them to rely on their own sense of awareness. These works need participants in order to be complete, as the viewer's act of looking and deciphering is the final part of the work. 


\section{Influences}

I have found the work of numerous movements and artists to be significant in my own studio practice and artistic investigations. Most important are those artists that make use of process and concept-based practices through the use of everyday objects and simple materials. Other influences investigate the use of industrial materials and the exploration of object, image and spatial ambiguity. Important to my understanding of this in the visual arts are artists included in Dada, Minimalism and the geometric abstractions of artists associated with the conceptual art movement in the 1960s. Specifically, the readymades of Marcel Duchamp, the concept or idea based work of Sol LeWitt (b. 1928), the process-driven works of Richard Serra (b. 1939), and the influence of materials, contextual awareness and processes of contemporary artists such as Rachel Whiteread (b. 1963) and Anish Kapoor (b. 1954).

"You do need to know some art history. As a producer of art objects/gestures, the conventions you decide to ignore and the conventions you decide to repeat are as important, if not more so, than what you invent."2

\section{Carol Bove}

I have an interest in restoring a voice to objects, materials, and environments that have been neglected or overlooked. I am greatly influenced by the ideas and works of the late Dada artist, Marcel Duchamp and his ability to provide insightful commentary on non-objectivity while finding visual appreciation for the cast-off junk of modern society and presenting the viewer with chaotic, contradictory, and ironic compositions.

Dada established a wide range of radical new techniques that shocked the art world in the early $20^{\text {th }}$ century. The employment of non-artistic materials and provocative exhibition installations and constructions has had a profound and lasting effect. In appropriating industrial goods as artistic materials, while also rebelling against traditional

\footnotetext{
${ }^{2}$ Editors, Artspace. "Book Report: The Four-Hour Art Week: Read Carol Bove's Self-Help Guide for Artists | Artspace." Artspace. (March 30, 2015) Accessed April 14, 2015.
} 
aesthetics, Marcel Duchamp marked a turning point in the Western understanding of creativity, unlocking new avenues for creative invention and the ability to push boundaries further than any previous artists or movements.

Dada's redefining of art is perhaps most effectively seen in Marcel Duchamp's "readymades". ${ }^{3}$ Concerned with found objects that he transformed into works of art simply by signing and placing them within an art context, Duchamp radically questioned the place of art in traditionalist society while disrupting all claims to individual creativity. ${ }^{4}$ His approach allowed him to bypass all stereotypical notions and expectations of artwork in order to establish a completely unprecedented and new type of art. When Marcel Duchamp first screwed a bicycle wheel to a kitchen stool in 1913, he had no obvious artistic intention. In fact, in his dialogues with journalist Pierre Cabanne he stated, "The word 'Readymade' did not appear until 1915, when I went to the United States. It was an interesting word, but when I put a bicycle wheel on a stool, the fork down, there was no idea of a 'readymade,' or anything else."5

The components of Duchamp's Bicycle Wheel (fig.1) were mass-produced and anonymous. By simply selecting prefabricated items and calling them art, he subverted established notions of the importance of the artist's craft and the viewer's aesthetic experience. At this time, such household objects could not be mistaken for artworks. Duchamp used these assumptions to attack more traditional works of art by simply displaying his readymades in art galleries. ${ }^{5}$

Over the years, there has been a dramatic redefinition of fine art galleries and the commitment to meet preservation challenges and continuously remake works. It is the readymade that opened the door for a limitless variety of these manifestations to enter the exhibition spaces. ${ }^{6}$ The readymade, and Duchamp's Bicycle Wheel, derives from multiple

\footnotetext{
${ }^{3}$ Duchamp, Marcel. New York Dada: Duchamp, Man Ray, Picabia; (Städt. Galerie Im Lenbachhaus, München, 1973), 11.

${ }^{4}$ Burger, P. Theory of the Avant-Garde. Minneapolis, MN: University of Minnesota Press. 1984, 2.

${ }^{5}$ Humble, P. N. "Duchamp's Readymades: Art and Anti-Art." The British Journal of Aesthetics 22, no. 1, 1982), 6.

${ }^{6}$ Buskirk, Martha. The Contingent Object of Contemporary Art. Cambridge, Mass.: MIT Press, $2003,10$.
} 
movements including the act of choosing the object from many others, as well as designation of authorship and re-contextualization.

It is the importance of museums and galleries as the spaces in which art is displayed and the first two of the operations associated with the readymade, that allow selection and designation to take place without the third, physical re-contextualization. Works executed outside the institutional spaces appear as objects, or actions, that might be scarcely unique from their surroundings, but are still accepted by those who are aware of their designation as art. With the readymade in particular, re-contextualization is possible because of the long-standing assumptions about artistic authorship as shown in Duchamp's In Advance of the Broken Arm (fig.2) from 1964. ${ }^{7}$ The first iteration was created in 1915 when he saw a pile of snow shovels with big square steel scoops lined up in a shop for the New York winter. He bought one and hung it from his studio ceiling after inscribing In Advance of the Broken Arm, from Marcel Duchamp, 1915. Aside from the inscription, the object was not modified. Duchamp added the inscription to provide what he called "verbal colour." indicated that though the object came from him, it was not made by him.

Authorship speaks to the integrity of the work of art based on the belief that the work of art is more than simply another commodity. However, when works of art are made using forms close to or identical with the realm of objects not defined as art, the designation of authorship may in fact be the only feature that distinguishes the work of art from any other object. ${ }^{9}$

The various steps in which Duchamp's work began to resonate tells a larger story about post-war art through the significance of the artists he influenced. Invited to design an installation for the 1942 New York exhibition First Papers of Surrealism (fig. 3), Duchamp choreographed a setting that foreshadows the work of Sol LeWitt. Duchamp draped and wound one mile of string from floor to ceiling through the exhibition space, creating physical impediments to those wishing to view the exhibition. Although LeWitt

\footnotetext{
${ }^{7}$ Ibid, 15.

${ }^{8}$ Ades, Cox, Hopkins, 150.

${ }^{9}$ Buskirk, 15 .
} 
knew nothing of Duchamp's installation, the Duchamp-LeWitt parallels are striking. Here LeWitt describes his own artistic practice, "dazzling the intellect put in the service of visual art; conceptual playfulness wedded to rigorously controlled form; ...the intersection of art and social issues; ... expression in a wide range of media; ... and, most obvious, unwavering commitment to art as idea." ${ }^{10}$ In his "Paragraphs on Conceptual Art" Sol LeWitt once stated "If the artist carries through his idea and makes it into visible form, then all the steps in the process are of importance. The idea itself, even if not made visual, is as much a work of art as any finished product. All intervening steps, scribbles, sketches, drawings, failed works, models, studies, thoughts, conversations are of interest. Those that show the thought process of the artist are sometimes more interesting than the final product." 11 This kind of art is no longer dependent on the skill of the artist as a craftsman.

The decisive contribution of Sol LeWitt's work to the emergence of Conceptual Art joined practices such as earthworks, installation art, performance and the creation of artist run spaces that challenged traditional thinking about the art object and its place in the world. It is these radical developments through the work of two generations of artists who sought to redefine the structures of art and rethink how it could be made, shown and supported. ${ }^{12}$ The rise of installation-based works over the past forty years has reached a point where the simple display of a series of paintings can be labeled as an "installation". Sol LeWitt's first wall drawing dates from 1968 (fig.4) and was originally created for the Paula Cooper Gallery in New York City. LeWitt's creation of a wall drawing was both sudden and radical. He had suddenly found a method where he could escape the limitations of paper and canvas, more importantly he could work directly on the wall or floor without the intervention of a support such as canvas or paper. In his own work, he changed the role of drawing as a modest medium into drawing on a large scale in architectural spaces.

\footnotetext{
${ }^{10}$ LeWitt, Sol, and Gary Garrels. Sol LeWitt: A Retrospective. San Francisco, Calif.: San Francisco Museum of Modern Art; 2000, 40.

${ }^{11}$ LeWitt, Sol. Paragraphs on Conceptual Art. Corner-college.com. June 1, 1967. Accessed April 14, 2015.

${ }^{12}$ LeWitt, Sol, and Gary Garrels. Sol LeWitt: A Retrospective, 89.
} 
In his 1971 Wall Drawing \#86, (fig.5), he demonstrated a related ambition regarding the scale of the work in relation to the gallery context, pushing the boundaries of installation art. The flourishing of installation work reflects the artists' desire to transcend the limits of individual objects and exact increasing control over what we might think of as the means of reception and display. ${ }^{13}$ With installation, there is always an attempt to challenge the limitations of individual objects through the pursuit of ideas by utilizing the architecture, engaging the walls, corners, and other structures as compositional schemas of the gallery.

Challenging limitations are crucial to the successful works of Richard Serra, along with his dependency on the inclusion of surroundings. Although extremely different in scale and concept, the works of Richard Serra relate to those of LeWitt, while cueing the viewer to meaning beyond the material. Both artists incorporate materials and formal aesthetics that appear to be anonymous in either character, or finish. Yet, the works of Serra make surprising use of scale, process, and arrangements of raw material that encourage the viewer's awareness and relationships to the object. This relationship is influential in terms of spatial awareness.

In Serra's sculpture, color, surface, texture, and shape help to emphasize the physical component of the work. While many of Serra's later works visibly command a certain space, his earlier drawings and wall prop pieces teeter between slippage and stability. In his 1968 piece, Bent Pipe Roll, Serra used two equal lengths of untreated pipe that were small enough to carry. These were then connected in the middle by a heavier and wider stretch of lead pipe (fig. 6). The two ends of the smaller pipes were bent at forty-five degree angles and joined the heavier conduit in an elbow like structure with three linear components and one smaller pipe resting on the floor entering into the viewer's space. The end closest to the wall was connected to the wider pipe, and balanced at ninety-degrees against the wall. Immobilized between the wall and the heavier pipe was the second smaller lead piece running up the wall to fifty-six inches tall. The resulting piece is a freestanding lead pipe that lies along the floor angling upward through a cylindrical lead roll, cautiously leaning against the wall. Serra's materials and

\footnotetext{
${ }^{13}$ Ibid, 95.
} 
process frame an experience of space and time in which one's visual perception of the work cannot be separated from one's bodily understanding of its presence. ${ }^{14}$

Although this piece is small in comparison to most of Serra's prop pieces of the late 1960s and 1970s, it is still heavy and relates directly to the scale of the viewer, casting a very stark shadow. The materials were arranged and presented out of their traditional utilitarian context, allowing for the process and surface of these works to become curious, and somewhat unfamiliar. The scale and material used by Serra refers back to physical relationships involving the viewer - the relative weight of an iron pipe, the height of a drawing, or the movement of material by human hand.

In a group of Serra's line drawings, studies of Circuit (1972), an installation of steel plates (fig. 7), there is a similarity between his drawing process and that of Rachel Whiteread, born in 1963. Like Serra, Whiteread installs large-scale sculptures in urban environments. She is best known for her cast replicas of built structures, such as Water Tower (1998), a life-size resin cast of a water tower. While making these preparatory sketches (fig. 8), Whiteread drew a water tower in yellow above buildings painted white. By using color and line drawing, Whiteread edited out the details in the same way that Serra edited out the lines of the gallery when drawing the edges of the steel plates in Circuit.

Fundamentally, Whiteread's work has little to do with the minimalist aesthetic of Richard Serra. On one hand, her work has a strong formal dimension - a concern for materials, process, texture, shape, scale and color. On the other hand, her casts of architectural spaces or ordinary objects of domestic use are anything but abstract and often come with heavy meaning. To detach an ordinary object from its utilitarian purpose is to reveal its formal abstract qualities, as Marcel Duchamp first showed in his readymades. Whiteread does the same by removing the doors, windows, bathtubs and sinks from their original context and primary function, casting them in concrete, plaster or resin, and exhibiting them in an art gallery. ${ }^{15}$

\footnotetext{
${ }^{14}$ Buskirk, 23.

${ }^{15}$ Dorment, Richard. "Rachel Whiteread, Gagosian Gallery, London, Review." The Telegraph. Accessed April 02, 2016. http://www.telegraph.co.uk/culture/art/art-reviews/9995657/Rachel-Whiteread-GagosianGallery-London-review.html.
} 
By casting an ordinary garden shed in concrete (fig. 9), she transforms a structure often found in a backyard into a minimalist sculpture. Since the casting process turns recesses into protrusions and vice versa, it allows one to see the underlying geometric patterns on the shed's exterior. "Such an object, elaborately made and inserted into the landscape can't be mistaken for anything but an aesthetic object." ${ }^{16}$ The three windows are easy to see as three blank rectangles, while the siding slats separated by regular intervals read as vertical and diagonal bands within a satisfying formal composition.

Every object Whiteread chooses to work with possesses a familiar, human resonance. Working on a wide-ranging scale, both within and outside the gallery, and with objects that people can hold, use and inhabit, she is fascinated with things that have been designed for human use. This fascination is embedded in her sculpture. The objects from which she casts are always second-hand; they have had a life prior to the artist's treatment of them, and bring their own history to the meaning of the casts she takes from them. ${ }^{17}$

Similar at times to the clearly articulated forms of Rachel Whiteread are the fundamental, yet abstract sculptures of Anish Kapoor. Kapoor expands upon his practice, using new treatments for materials and creating innovative forms, including large-scale stainless steel works (fig. 10) that transform and reactivate the gallery space. Expanding upon the familiar, while introducing new methods of configuration, these works build upon his signature style while teasing out new directions for Kapoor's formal investigations. $^{18}$

Recently, Kapoor has stretched the limits of his expertise with several monumental sculptures whose materiality and sense of scale not only create new positions for the viewer's eyes to engage the work, but also manipulate and recontextualize space. The success of Kapoor's Cloud Gate (fig. 11) is especially surprising given the fate of other major works of public art in recent decades, such as Richard Serra's Tilted Arc (fig. 12), which was torn down due to public opposition. With Serra's

\footnotetext{
${ }^{16}$ Drucker, Johanna. Sweet Dreams: Contemporary Art and Complicity. Chicago: University Of Chicago Press, 2005, 52.

17 "Rachel Whiteread: Shedding Life Tate." Accessed April 01, 2016. http://www.tate.org.uk/whats-on/tateliverpool/exhibition/rachel-whiteread-shedding-life.

18 "Exhibition - Gladstone Gallery." Accessed April 02, 2016. http://www.gladstonegallery.com/exhibition/1850/press.
} 
Tilted Arc a curved wall made out of a single piece of raw steel, 12 feet high and 120 feet long, was installed in the middle of New York's Federal Plaza in $1981 .{ }^{19}$ Slightly tilted, the wall bisected the plaza, forcing workers in the surrounding office buildings to navigate around it. From the outset, Tilted Arc instilled a sense of social anxiety. After years of litigation, it was finally removed in 1989.

Tilted Arc was no more abstract or monumental than Cloud Gate, but the message or of Serra's work is almost the exact opposite of Kapoor's. Kapoor's work privileges virtual experience, while Serra's insists on sensual immediacy. Cloud Gate is about lightness and futurity. Tilted Arc was about gravity and weight. Cloud Gate, designed to obscure the process that went into its manufacture, looks impossibly new. Formed out of COR-TEN steel, Tilted Arc looked as if it came straight out of the blast furnace and quickly developed a patina of orange rust. Whereas Cloud Gate's skin conceals its structure, Tilted Arc insists on structure as form. The real anxieties surrounding Tilted $A r c$ had very little to do with urban blight, and everything to do with the unease engendered by what is perceived as an outdated socio-economic order. ${ }^{20}$ Tilted Arc revealed what Cloud Gate and Millennium Park were built to efface, and that is why it had to be torn down.

Kapoor's signature use of dynamic material and organic forms to dominate, astonish, and redefine the relationship between object and viewer, sculpture and space, are important in my conceptual balance of things familiar and unfamiliar combined with a surprising balance of materials or process.

\section{SOMEWHAT FAMILIAR}

The works presented in this exhibition address my investigation into extending Minimalism's interest in anonymity and relational aesthetics, while adhering to my own predetermined parameters. I am inspired by observed form and composition, along with the transformation of mundane and knowable materials into uncertain sculptures that

\footnotetext{
19 "Cloud Gate, Tilted Arc| The Point Magazine." The Point Magazine Cloud Gate Tilted Arc Comments. ${ }^{20}$ Ibid. 2012. Accessed April 15, 2016. http://thepointmag.com/2012/criticism/cloud-gate-tilted-arc.
} 
highlight their physical properties. Emphasis is placed on the material presence of the work and spatial ambiguities, while rejecting the norms of traditional artistic production.

SOMEWHAT FAMILIAR (fig. 13), consisted of several sculptural arrangements that made use of familiar construction materials such as lumber, drywall, steel remesh, vinyl siding and oriented strand board (OSB). These works were installed in the Laura Mesaros Gallery in reaction to the physical objects found in our everyday built environment. The exhibition was a combination of painting, multiple free-standing sculptural works, five wall-mounted photographs and one four-walled space encouraging viewer involvement. The works required an audience willing to spend a moment in the experience of looking and made use of re-contextualization of objects that create confusion between a useful object and an art object.

\section{The Exhibition}

Drawing inspiration from 1960's and 1970's Minimalism and Conceptualism, SOMEWHAT FAMILIAR aimed to accentuate the limits and effects of formal art spaces, while turning one's attention toward certain industrial textures and materials that surround us every day. Relating to contemporary curating techniques, the exhibition forced the viewer to move around (or inside) the works, contrasting the stationary nature of these solid materials. Formal and dynamic movement was created through the manipulation of lighting to emphasize the shadows of the individual pieces and overall space.

Upon walking into the Laura Mesaros Gallery, the viewer entered a space where the light was focused on a piece titled Model \#: 1248LLT080000 Study ${ }^{21}$ (fig. 14). It is an 18 "x20" sheet of drywall centered 60 inches from the floor on the right entry wall. Running horizontally across the flat white painted sheet of drywall was a four-inch wide relief. A wooden jig was installed across the drywall sheet, positioning the bottom of the jig at 62 inches. After installing the jig, a Porter Cable 2-Amp Orbital Sander was used to sand through the drywall until breaking through the paper resulting in rigid and soft shadowed outlines formed from by the recessed section.

\footnotetext{
${ }^{21}$ The titles of each piece relied on the Lowe's hardware store model number of the most used material within the piece.
} 
Model \#: 1248LLT080000 Study plays with the inherently flat surface of the gallery and relates back to the construction of the wall in which it has been installed. One screw was placed in each of the four corners and then patched, sanded flat and painted over in flat white paint encouraging the viewer to question where and how the piece was created. This piece in particular made surprising use of gallery rules and expectations (the typical height of displayed work 60 inches) and the use of traditional construction materials

Continuing from the entryway down the curved ramp, the viewer passes by a framed painting isolated in the gallery's far right corner. This section is awkwardly cut-off from the rest of a rather long rectangular room thanks to the ramp's handrail and the resulting raised triangular platform. This is the most inaccessible space in the gallery. Model \#: 646214 (fig. 15) is centered again at 60 inches on center and is a framed painting made by tirelessly power sanding the OSB until the original rough texture was consistently flat across the sheeting.

Contained within the thirty-four inch by forty-four inch rectangular composition was a six-inch by twenty-two inch thick impasto-like white rectangle composed of several layers of Premixed All-Purpose Drywall Joint Compound. This rectilinear space had been taped off with blue painters tape and a black chalk line had been dropped horizontally across the center of the contained area in reference to the horizontal landscape of the built environment. Multiple applications of joint compound were then applied and left to dry to approximately 80 percent. This rectangle was then painted with flat white gallery paint and left to dry for ten minutes. Once the restricted rectangle reached its desired texture, it was then assertively chipped away using a drywall knife for a period of thirty seconds resulting in the haphazard, yet controlled imagery that mimics the uncontrolled overlap found within the sanded strand board.

Slightly more experimental in character than the previous work, this piece was more literal and narrative due to its materials and landscape based composition. Its form was less tentative in appearance, yet was possibly the most experimental piece within the exhibition. Subsequently, it was similar to Model \#: 1248LLT080000 Study in its function and accompanies the other works to form a statement on the formal simplicities of routine construction practices. 
Stretching along the longest wall of the gallery just beyond the end of the ramp was Model \#: 737624 (5) (fig. 16). Five framed photographs, each 34 inches in width and 44 inches in length and the top of each image hung at seven feet. Each photograph contained the same sheet of 3.5 foot by 7 foot steel remesh (previously lit and photographed in the same exact spot in the Laura Mesaros gallery in which the corresponding photograph hung during the exhibition). The horizontal and vertical linear shadows found in all five photographs were the result of systematically documenting the remesh end-on-end with the same lighting configurations. The remesh (while sitting on found wooden blocks) was moved end-on-end until reaching the gallery handrail that interfered with the composition.

Spaced exactly 15 inches apart and extending nearly twenty feet along the wall, the light wood framed photographs created a large sense of scale and complexity that encouraged the viewer to investigate the exact location in which the images were situated. Drawing attention to small, yet significant changes to each image activated one's spatial awareness and prompted one to question their location within the piece as a whole.

Roughly ten feet in front of the five photographs, placed directly on the floor and situated in the middle of the gallery was Model \#: 737624 Compressed at 185lbs (fig. 17). Sitting atop a light wood framed panel was the single sheet of steel remesh that had been used in the previous photographs. The grid from the once pristine rectilinear remesh had been compressed or wrestled into the smallest form possible, using only my arms, legs and core to manipulate the grid. This process also dictated part of the title, compressed at 185 pounds. The resulting form appeared to be denser in volume at the center and dissipated towards the edge. Lit directly overhead and from multiple cross sources, the viewer could approach the piece and not realize where it began and ended as the various shadows created a multi toned drawing that was cast upon the stark white framed panel board (fig. 18).

Its ambiguous nature was meant to create new positions for the viewer's gaze to engage the work, as well as manipulate and re-contextualize the space. Due to the location on the floor, economy of space, and overall simplicity of material transformation from one thing to another, I felt that this was the perfect piece to anchor the center of the 
room.

Further back in the left corner of the gallery, stood Model \#: 531659 A (fig. 19), composed of four white vinyl sided panels. Each of the four panels stood nearly eight feet high and six feet wide, and were joined together at each end to form a large white cube. Georgia-Pacific Vinyl Siding Vision Pro White Wood Grain Double 5 Traditional Vinyl Siding sheets were cut to length and assembled top to bottom on all four panels. The panel facing the back wall of the gallery was slightly different from the rest in that there was four rectangles cut from the underlying OSB. This panel was then backlit with four strategically placed fluorescent light bulbs that illuminated through the cut rectangles, creating a soft yellow glow through the vinyl siding similar to the light of a residential window at night (fig. 20). Special attention to lighting in this area of the gallery was required so that the subtle projections of light were not erased by the spot lighting overhead. The intent was to create less of a spotlight on the piece and give the piece an increased sense of wonderment. Expanding upon the familiar, while introducing new methods of configuration, this exterior piece builds upon my formal investigations into the built environment.

Making use of the twenty-foot high ceilings, as well as the slightly angled rear third of the gallery, the simple form of the cube was given enough space to exist independently of other works with little visual interruption or forced boundaries. Continuing around the form past the illuminated panel, the viewer was presented with a six foot, one inch tall by twelve-inch wide rectangular cutout allowing the viewer to enter the interior of the cube. The dimensions of the cutout offer a subtle reference back to the artist, as they are my standing profile height and width presenting the viewer with the opportunity to enter the structure if they are able to fit within the restricted dimensions.

Upon entering the interior of the cube Model \#: 1248LLT080000 (6) Reduced (fig. 21) was a four-inch wide, horizontal sanded relief that wrapped seamlessly from one wall to the next. This power sanded relief was created in the same intense and time-consuming fashion as Model \#: 1248LLT080000 Study, however this iteration took over six uninterrupted hours to complete and was determined finished when the paper had been sanded through on all four walls.

The combination of white drywall dust and brown paper particles that fell to the 
gallery floor during the act of sanding were left on the floor inside the cube while the exterior gallery floor had been cleaned (fig. 22). When the viewer exited the cube, they would bring the detritus into the clean gallery space, which created a soft pathway from one work to the next. The interest in this piece was driven by revisiting the material and spatial considerations of the Minimalist movement of the late 1960s and early 1970s and similarly revisited interests in the recent work of Rachel Whiteread and Anish Kapoor.

The last piece in the exhibition was Model \#: 1248LLT080000, a sculpture that sat between the front end of the left wall and the bottom of the ramp wall. Sitting waste high, were two sheets of four-foot by eight-foot drywall (fig. 23), both pieces of drywall had been manipulated by cutting and laminating. Each sheet of drywall was ripped into two inch wide strips, one was cut horizontally and the other vertically, and laminated together using ModPodge. The top plane of each of the two panels was then sanded down resulting in a soft formal composition referring back to minimal paintings of the 1960's.

The vertically cut panel was then laid atop two fabricated sawhorse style fixtures. These fixtures were connected in the middle with two horizontal pieces of planed KilnDried Whitewood Stud two inches by four inches. Extra attention was spent on the small details, as all screw holes were filled with Madison Mill Poplar Toy Miniature plugs; removing the objects from their intended rough construction usage. The horizontally cut panel was then propped diagonally onto the other two underlying objects emphasizing the horizontal, vertical and diagonal lines. Strong spot lighting was able to bounce around behind each piece casting shadows on the flat panel and floor creating an interesting composition. Due to the floating distance from one panel to the next, the shadows of each piece were cast in several different directions (fig. 24), often overlapping and creating areas of ranging dark and light shadows. Similar to the other works in the gallery, these pieces invited close physical inspection, while also obscuring a large portion of material. The sanding of the laminated panel surface invited the viewer to peer behind, but not enough to see the totality of what was presented. These pieces relied heavily on formal configurations and delicate connections to create a visual balance between the materials.

\section{Conclusion}

While I feel that most of the work focused on overworking and the manipulation 
of construction materials, the remainder of the exhibition explored the specifics of installation and spatial awareness. The titles of each piece relied on the Lowe's hardware store model number of the most used material within the piece. With the installation of the work, I decided to keep all wall labels away from the work, placing them four feet to the left or right of each work and fifty inches above the gallery floor. I did not want the wall labels to create a visual distraction to the work, nor did I want them to interfere with the viewer's interaction with individual pieces. In this sense, I think each work was better titled as a group; however, I wanted the viewer to know every material used within the creation of the piece, as each material was equally important. Without each material, the piece is unsuccessful.

Another example of simplicity and spatial awareness was the placement and location of the each piece within the gallery. Each piece was precisely placed in the gallery, encouraging the viewer to experience the works in a certain order. Dramatic lighting became a key concern as I chose to use the natural shadow within each piece to highlight certain aspects of the materials. Similarly, the inclusion of linear floor and wall shadows created a visual pathway leading the viewer from one piece to the next, encouraging the viewer's awareness and relationships to the objects.

SOMEWHAT FAMILIAR was an attempt to address my investigations into extending Minimalism's anonymity and relational aesthetics while adhering to my own predetermined artistic parameters. I placed emphasis on the material presence and spatial ambiguities of the work, while rejecting the conventions of sculpture and painting as mainstays of artistic production. By exploring this impulse to put everyday objects together, I stressed the subtle relationships that question the viewer's experience. It was my hope that the viewer would start to see these ordinary things, settings, and dependencies in new ways. In addition, keeping the viewer poised in a state of slight unease, and making them highly aware of their own physicality within the space, forced them to rely on their own sense of awareness. 


\section{Illustrations}

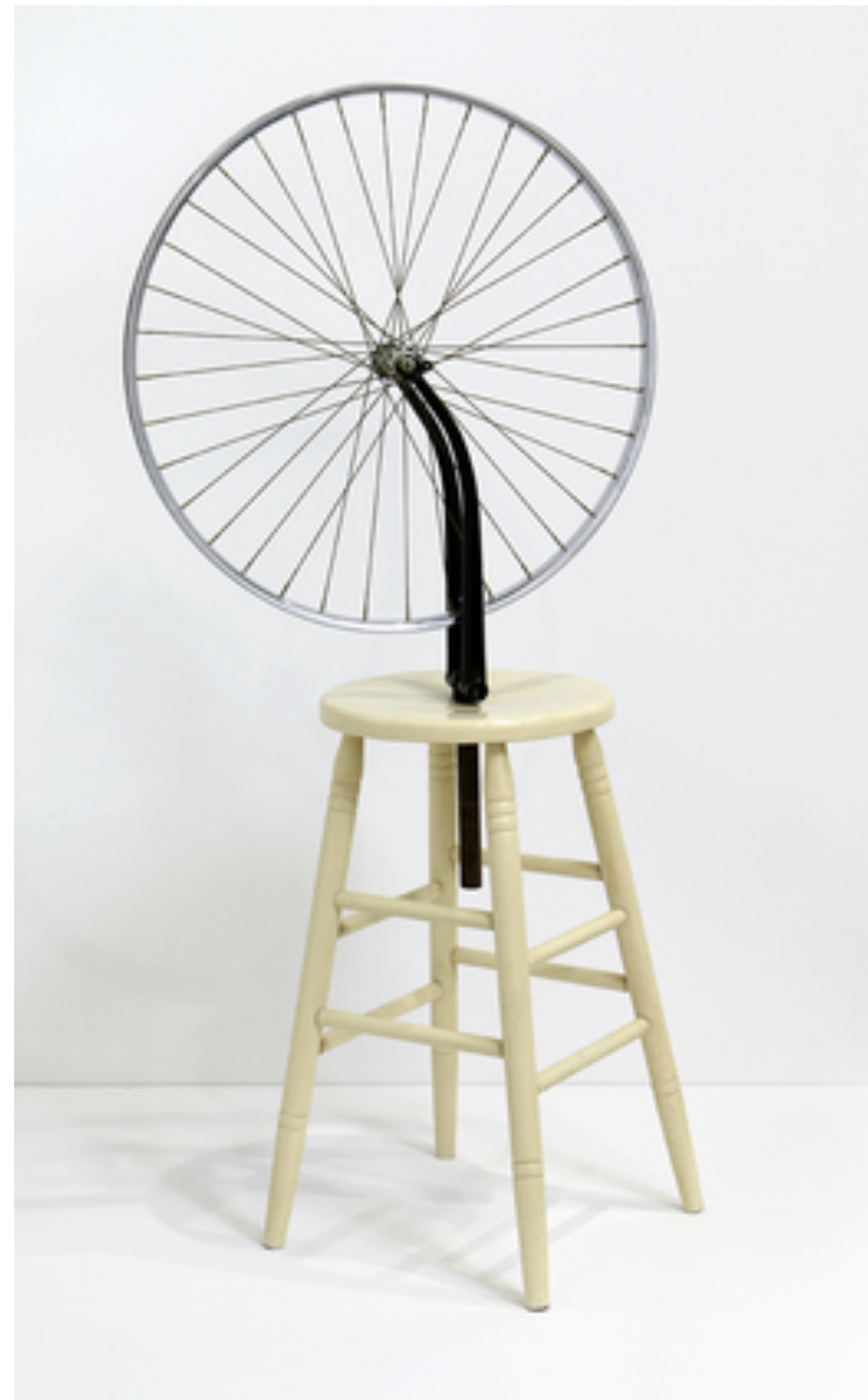

Figure 1. Marcel Duchamp

Bicycle Wheel

Metal wheel mounted on plastic wood stool

51 "x 25 "x $161 / 2 "$

1913 


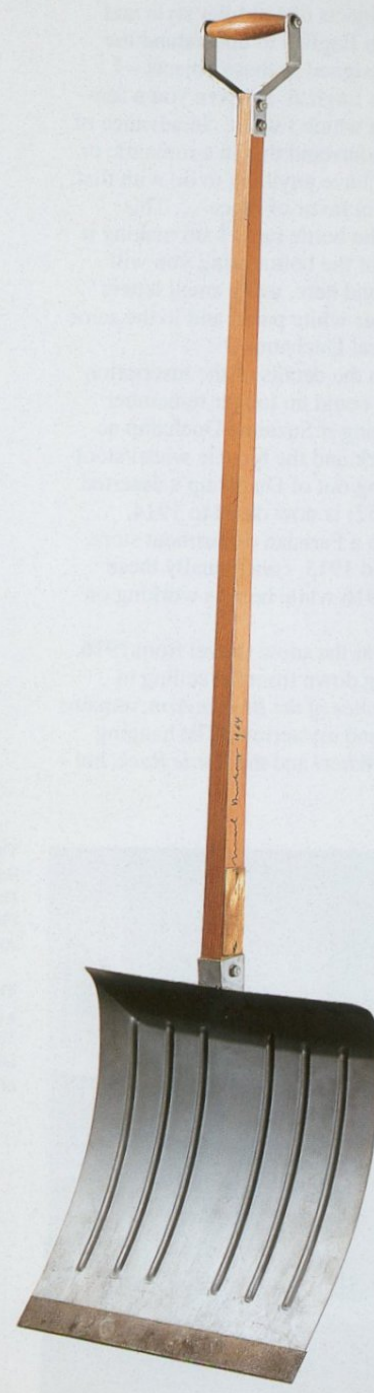

Figure 2. Marcel Duchamp In Advance of the Broken Arm Wood and galvanized-iron snow shovel $52 "$ tall 1964 


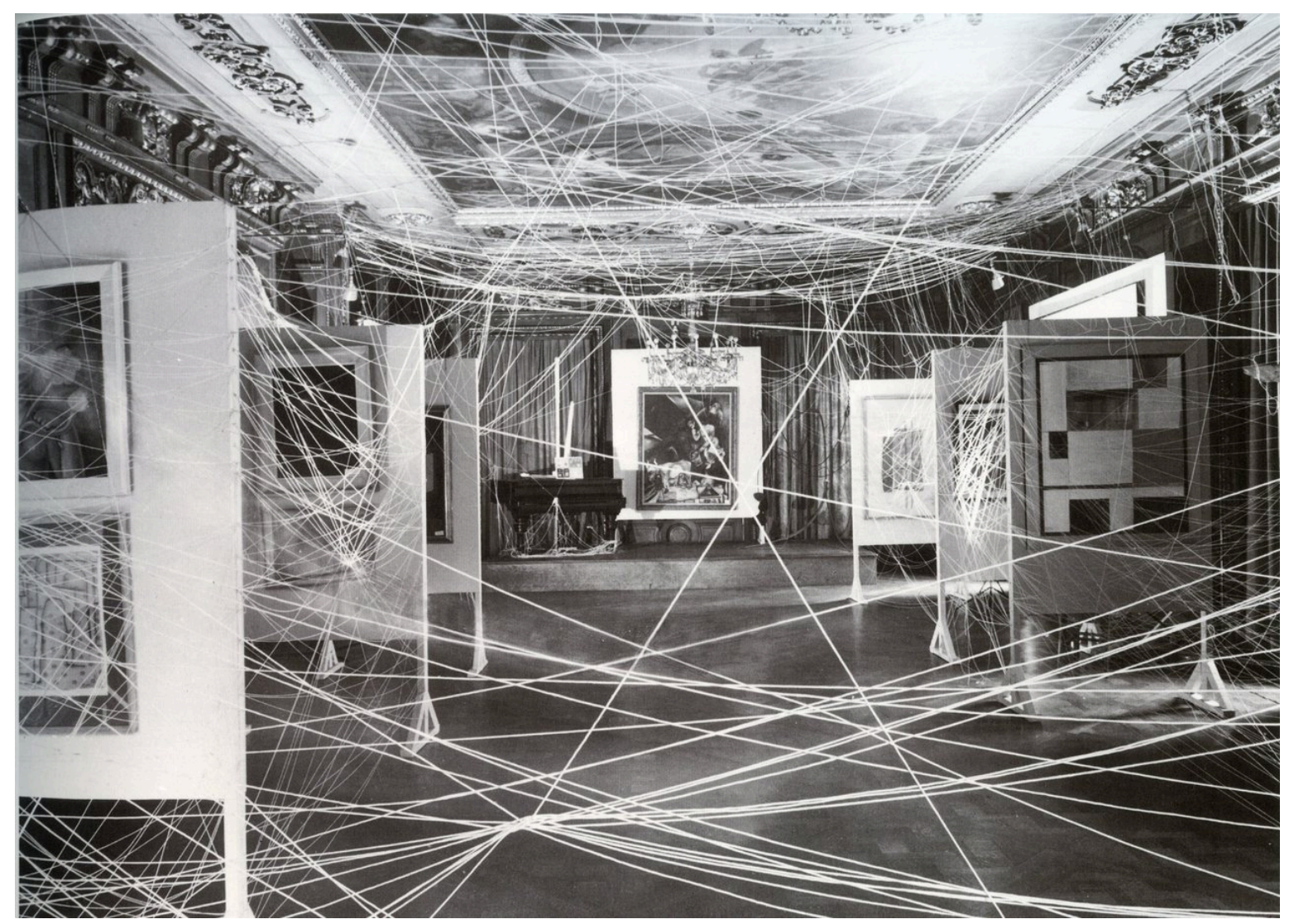

Figure 3. Marcel Duchamp

First Papers of Surrealism

Installation view of First Papers of Surrealism exhibition, showing Marcel Duchamp's His Twine

Gelatin silver print

1942 


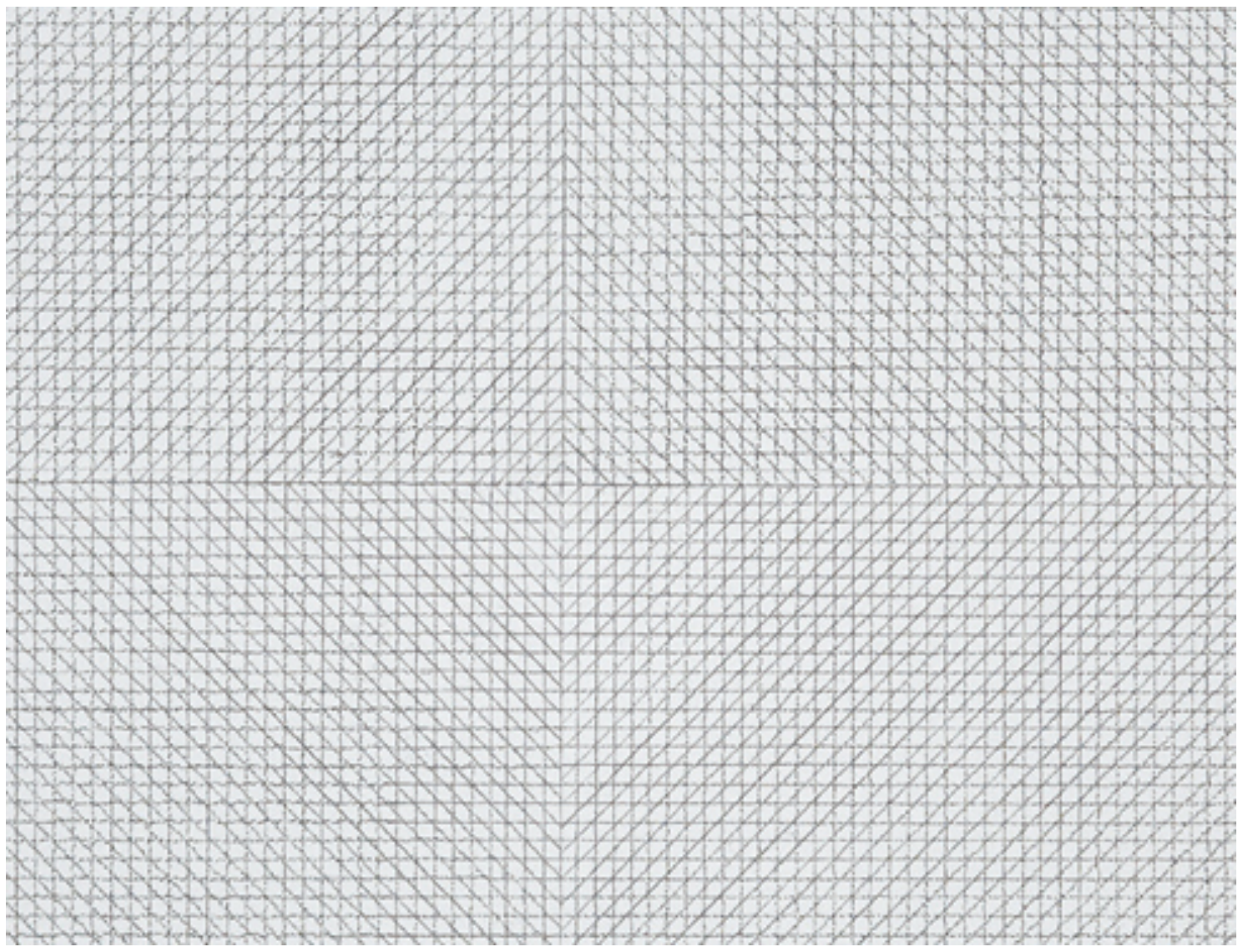

Figure 4. Sol LeWitt

Wall Drawing \#11

Black Pencil

1968 


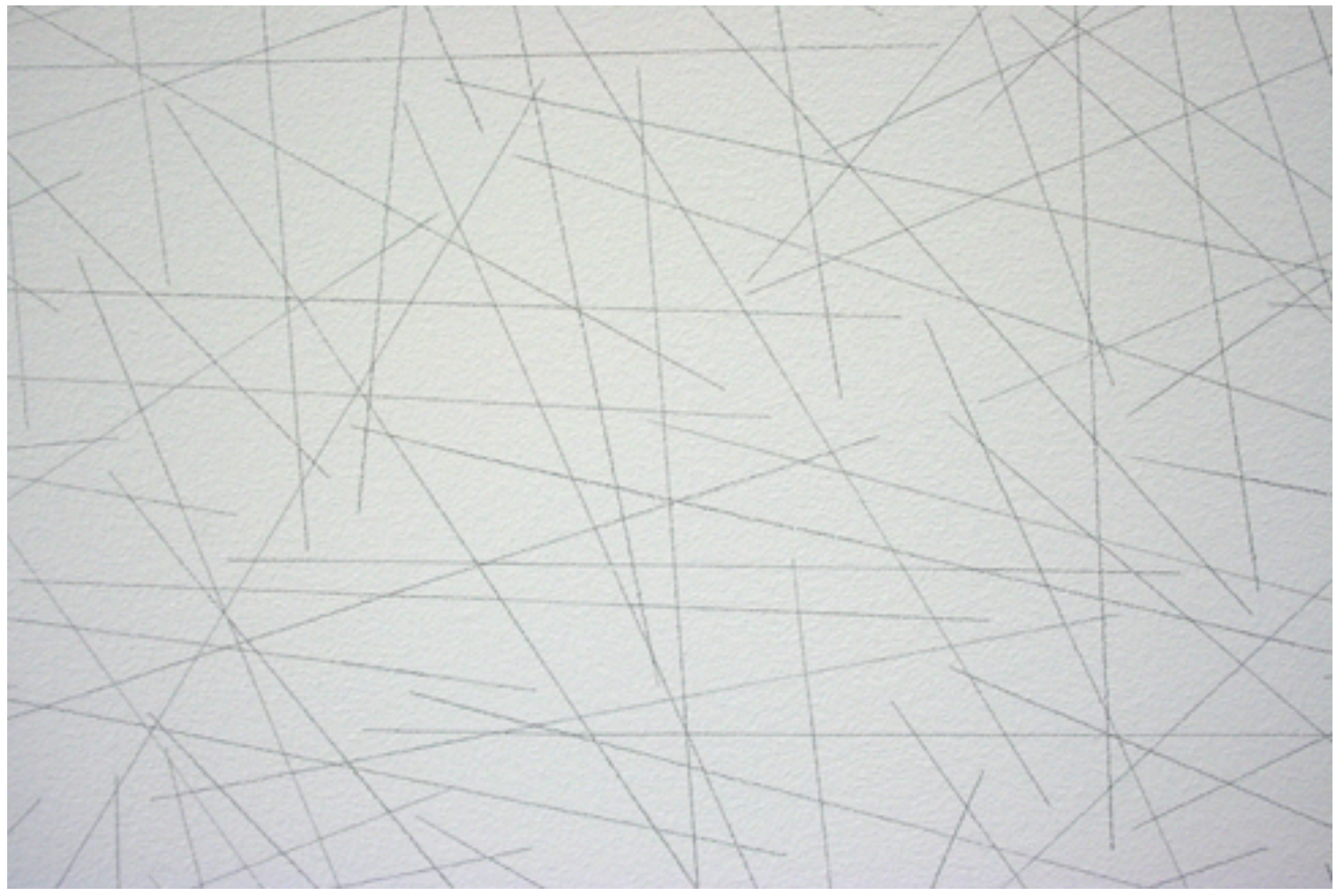

Figure 5. Sol LeWitt

Wall Drawing \#86

Black Pencil

1971 


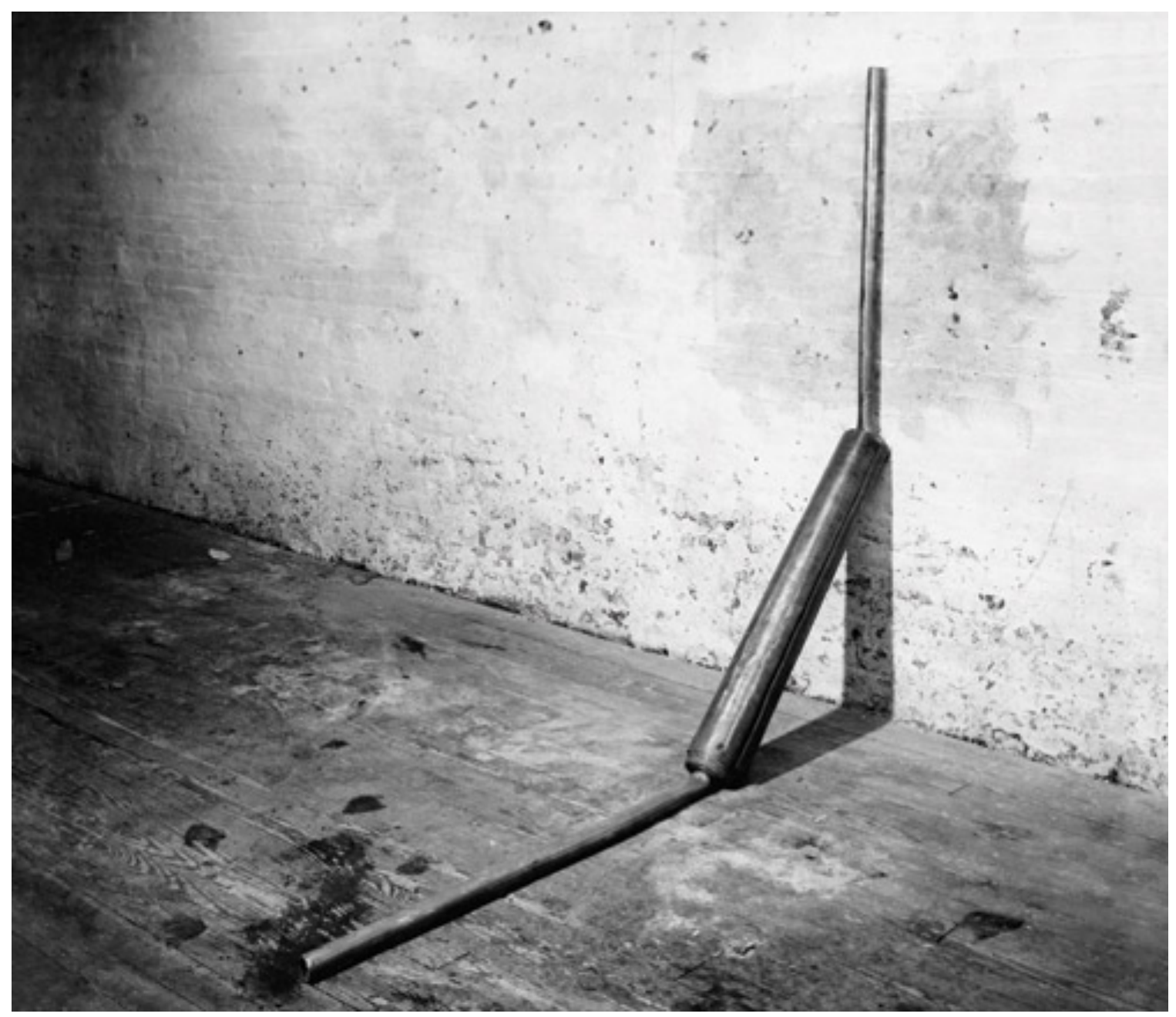

Figure 6. Richard Serra

Bent Pipe Roll

Lead

56" high; roll 6" diameter; 50" deep Collection the artist 1968 


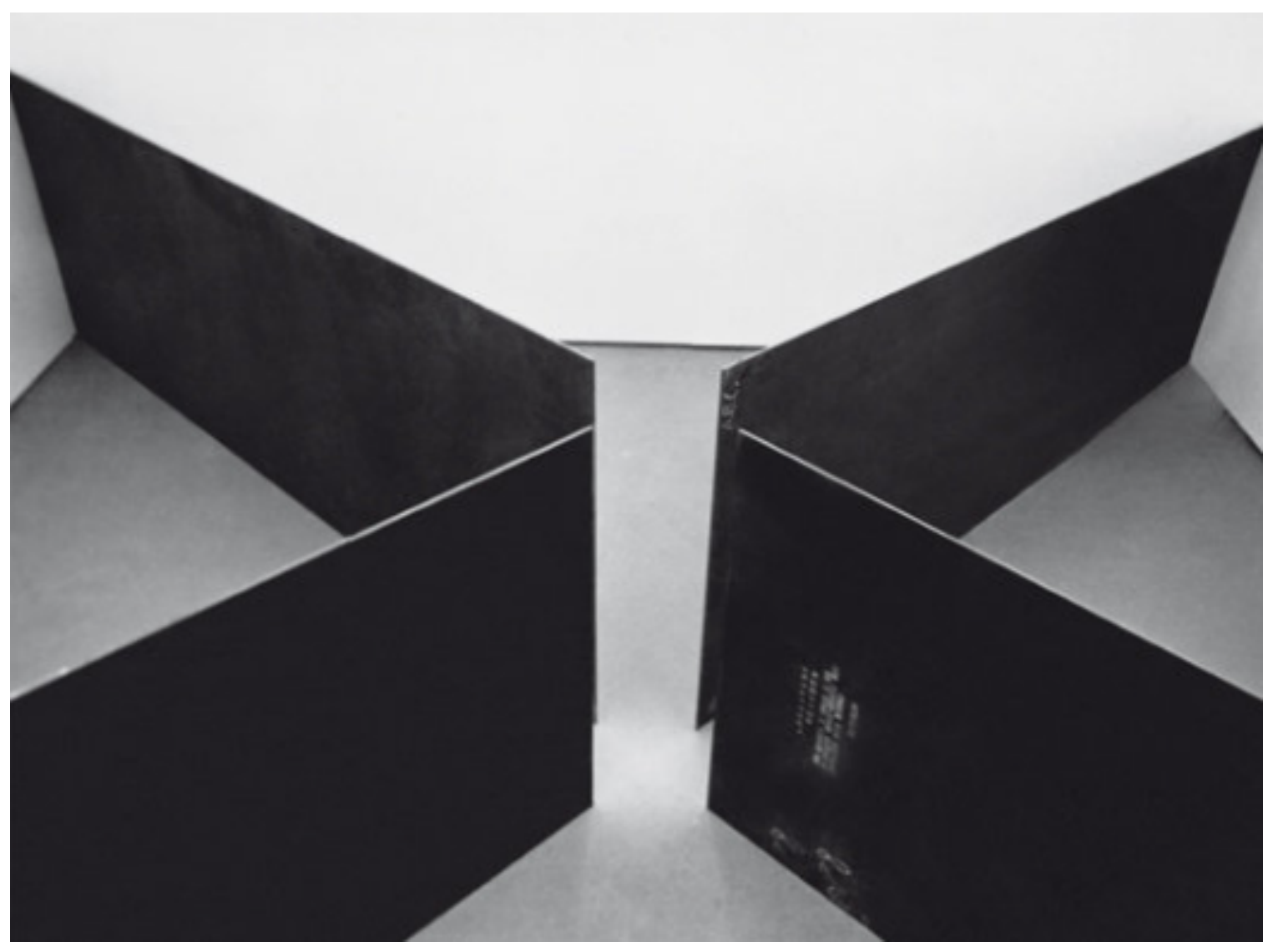

Figure 7. Richard Serra

Circuit

Hot-rolled steel, four plates

Each 8'x 24'x 1'

1972 
Figure 8. Rachel Whiteread

Drawing for Water Tower III

Correction fluid, varnish, pencil, and ink on graph paper

33 1/8" x 23 1/4"

1997 


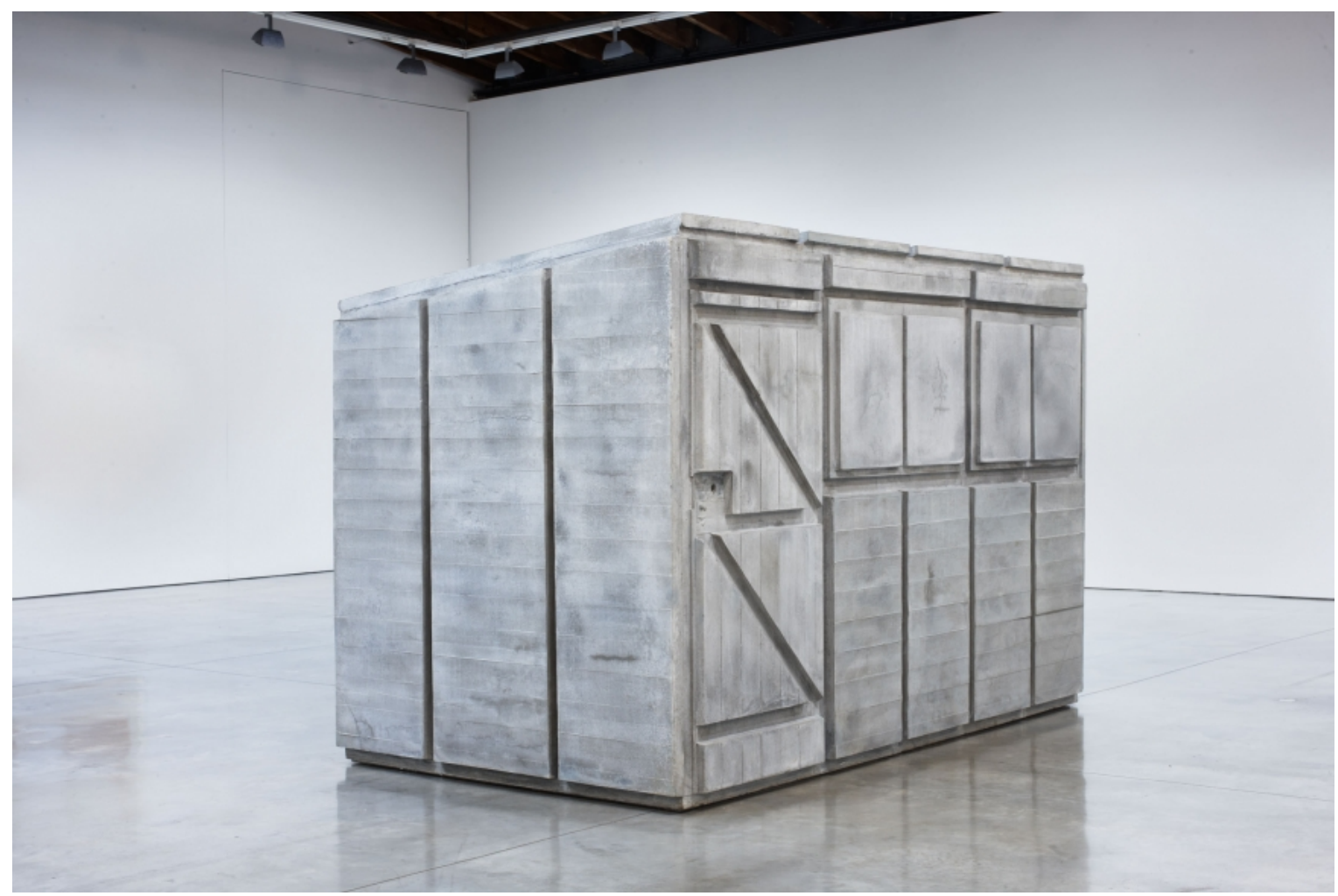

Figure 9. Rachel Whiteread Detached III

Concrete and steel sculpture cast from a prefabricated, wooden garden shed 78 3/4"x 67 11/16"x 42 15/16" 2012 


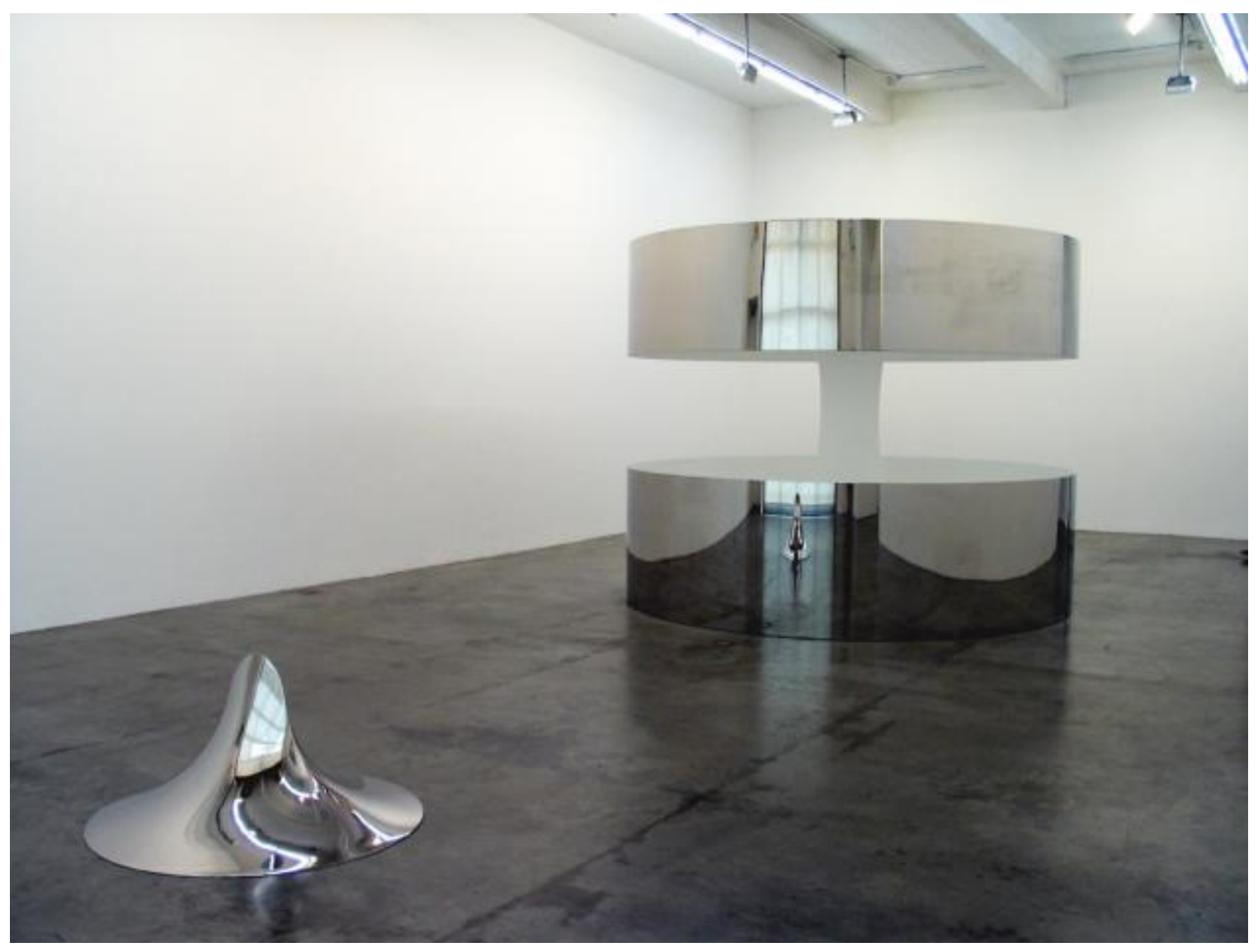

Figure 10. Anish Kapoor

Whiteout (Exhibition view at Gladstone Gallery)

Stainless steel

2004 


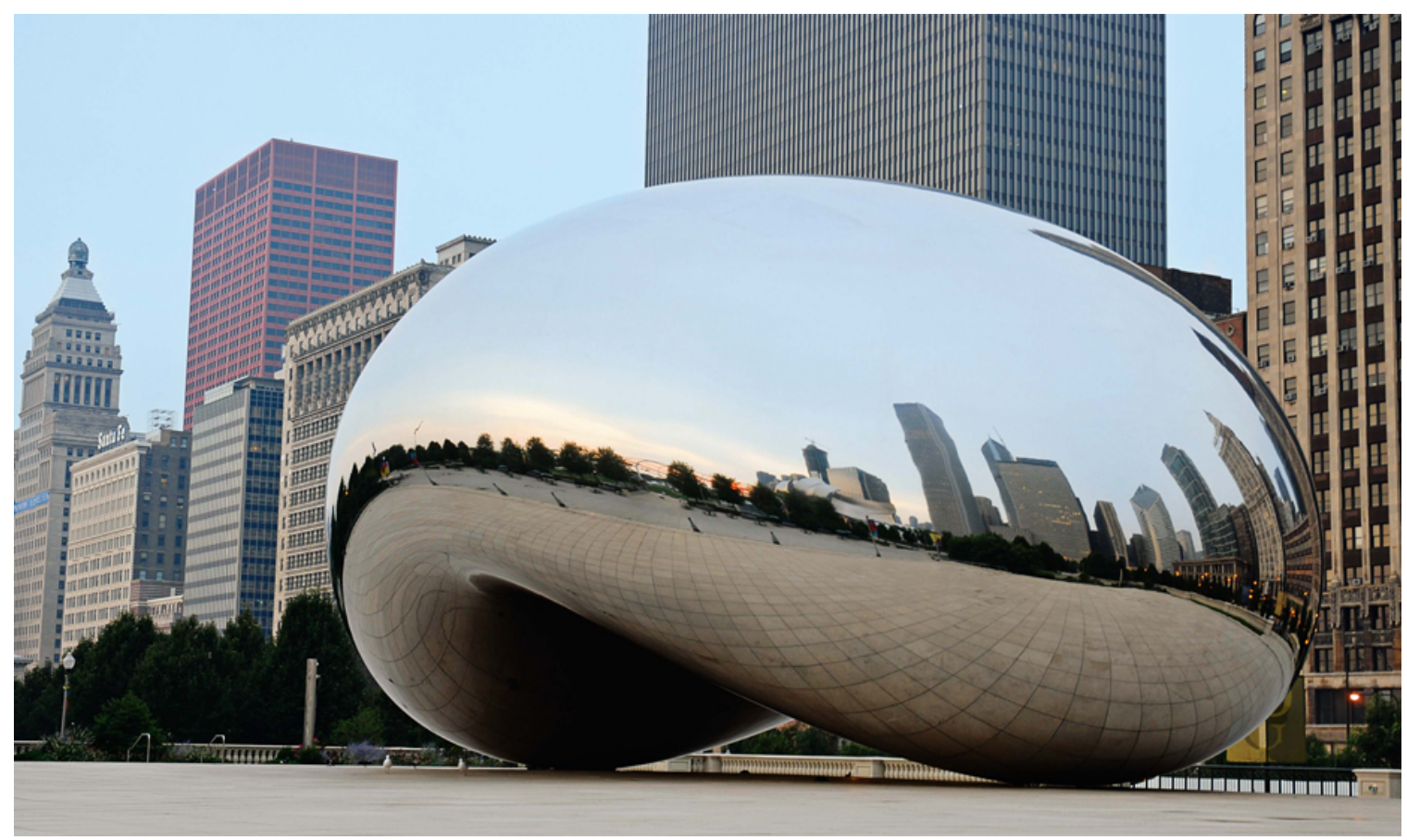

Figure 11. Anish Kapoor Cloud Gate

Stainless steel, $10 \times 20 \times 12.8 \mathrm{~m}$

2006 


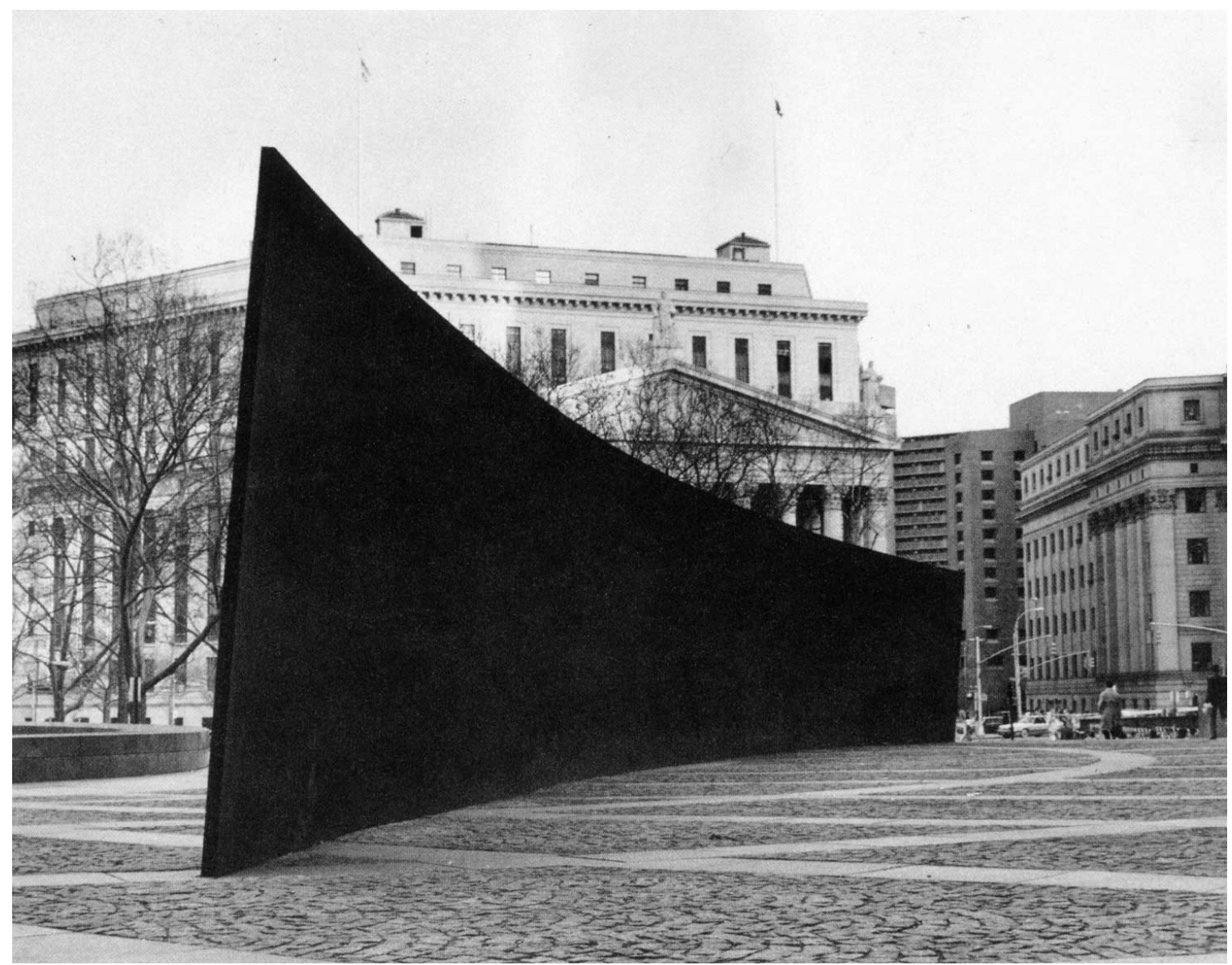

Figure 12. Richard Serra

Titled Arc

COR-TEN steel, 120' long, 12' tall, and 2.5" thick 1981 


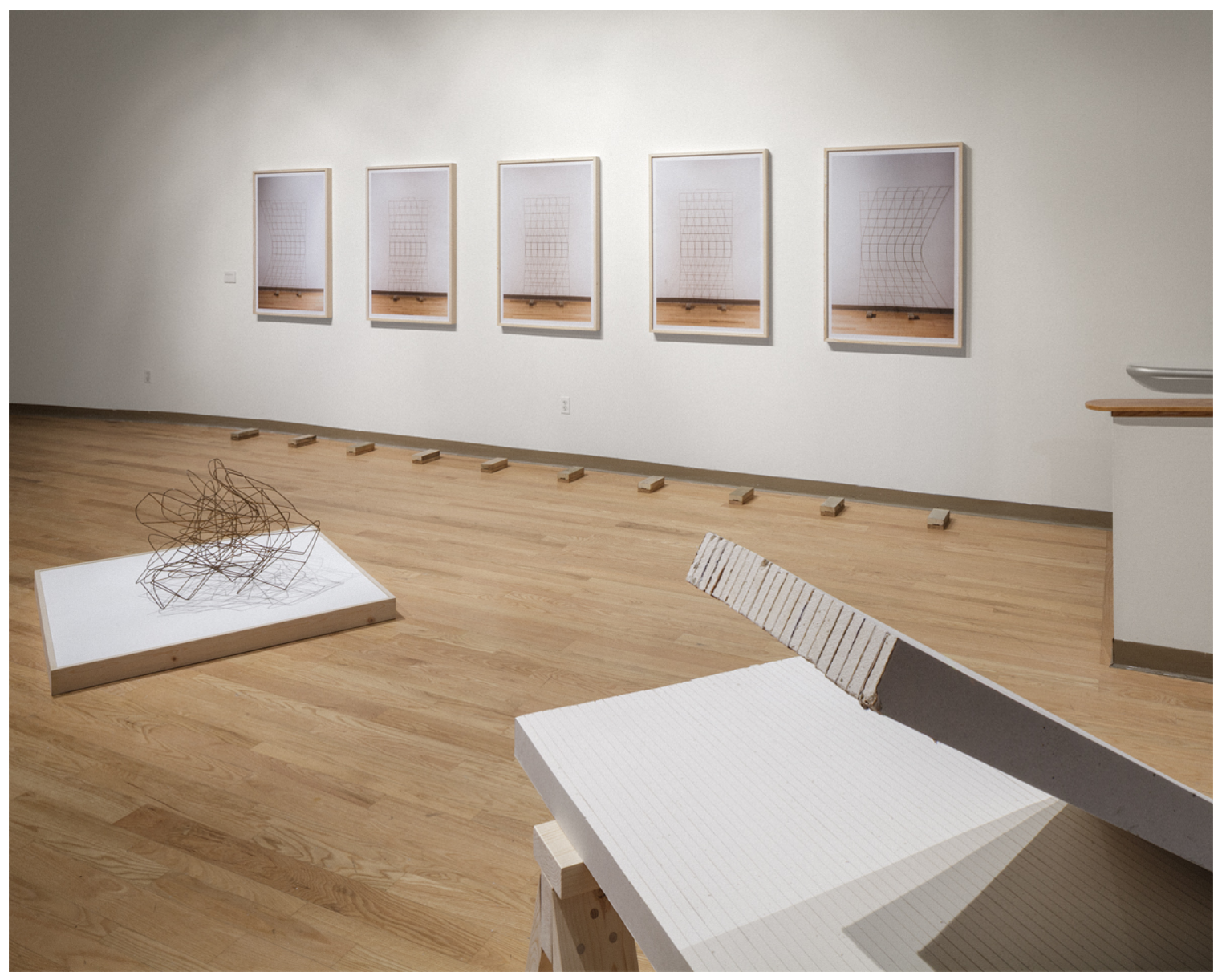

Figure 13. SOMEWHAT FAMILIAR exhibition view Laura Mesaros Gallery

2016 


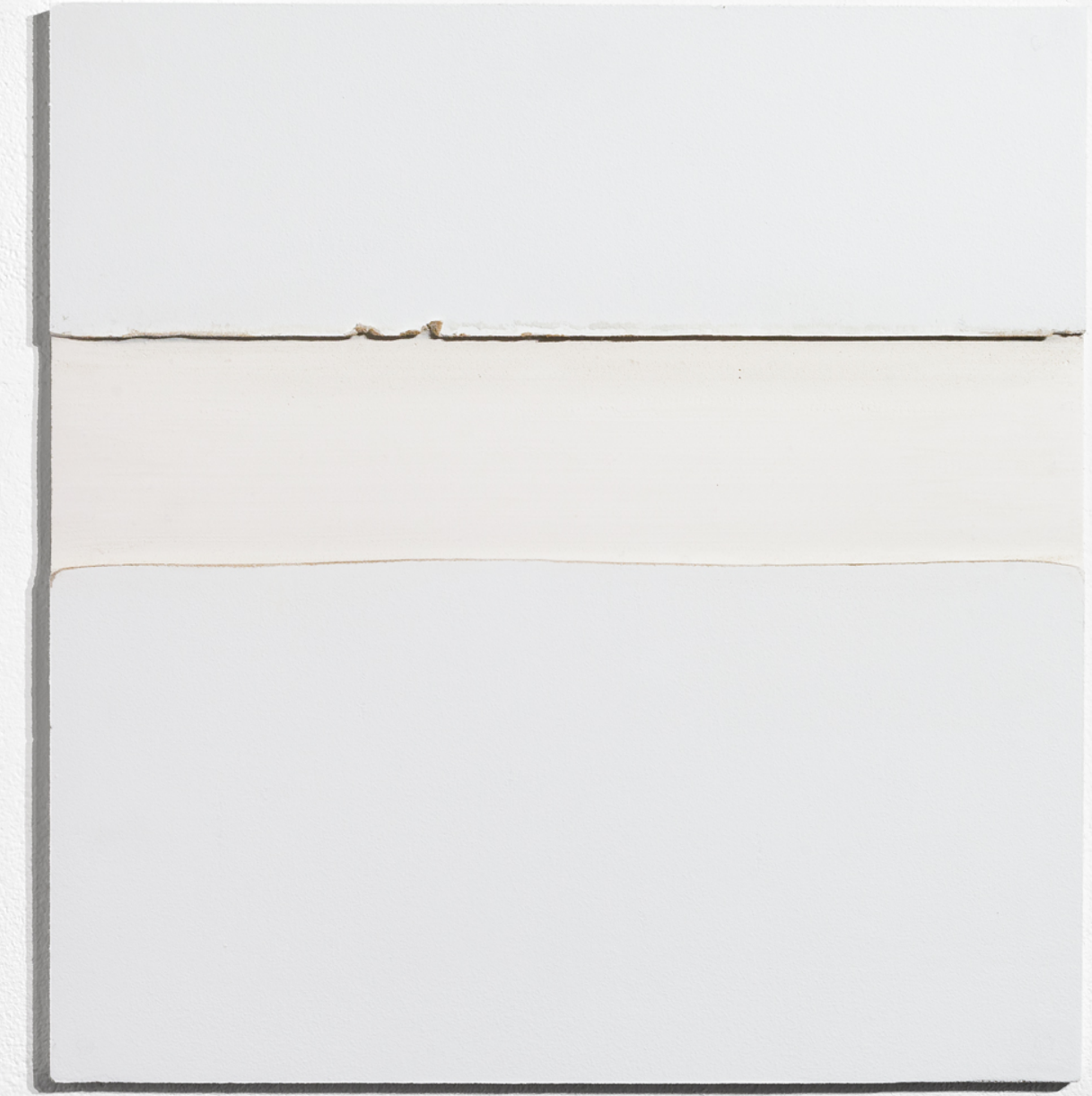

Figure 14. Model \#: 1248LLT080000 Study

Continental Building Products LifeLite Drywall Panel cut at 18"x20", Grip-Rite 25-lb \#8 x 1.625-in Bugle-Head Black Phosphate Drywall Screw, Valspar

Signature White Flat Latex Interior Paint, ProForm All Purpose Premixed All-Purpose Drywall Joint Compound

18 "x20"

2015 


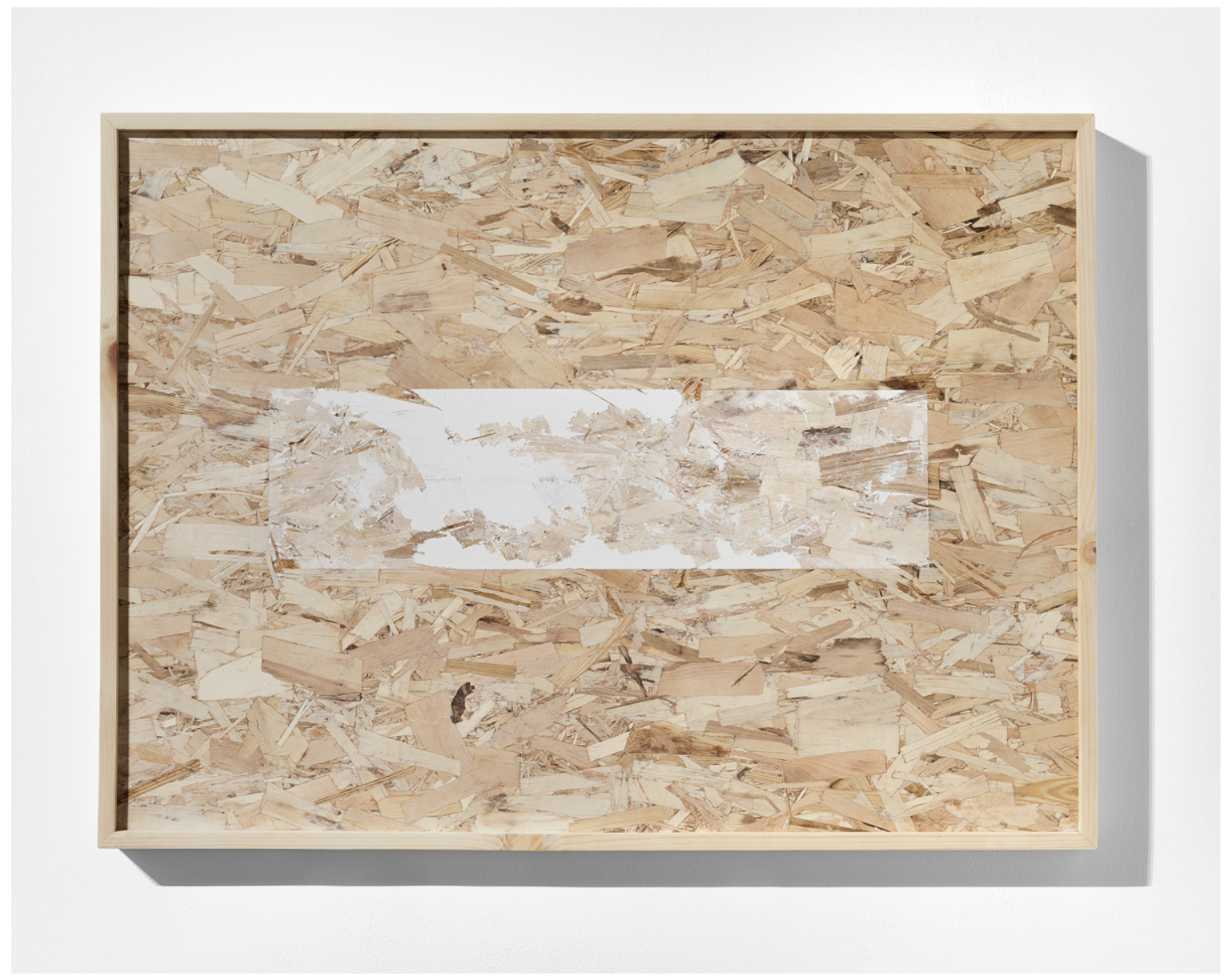

Figure 15. Model \#: 646214

OSB Sheathing 7/16 CAT PS2-10, Valspar Signature White Flat Latex Interior Paint, IRWIN Strait-Line 8-oz Black Permanent Chalk, ProForm All Purpose Premixed All-Purpose Drywall Joint Compound, Kiln-Dried Radiata Pine Softwood Board 34 "x 44 "

2015 


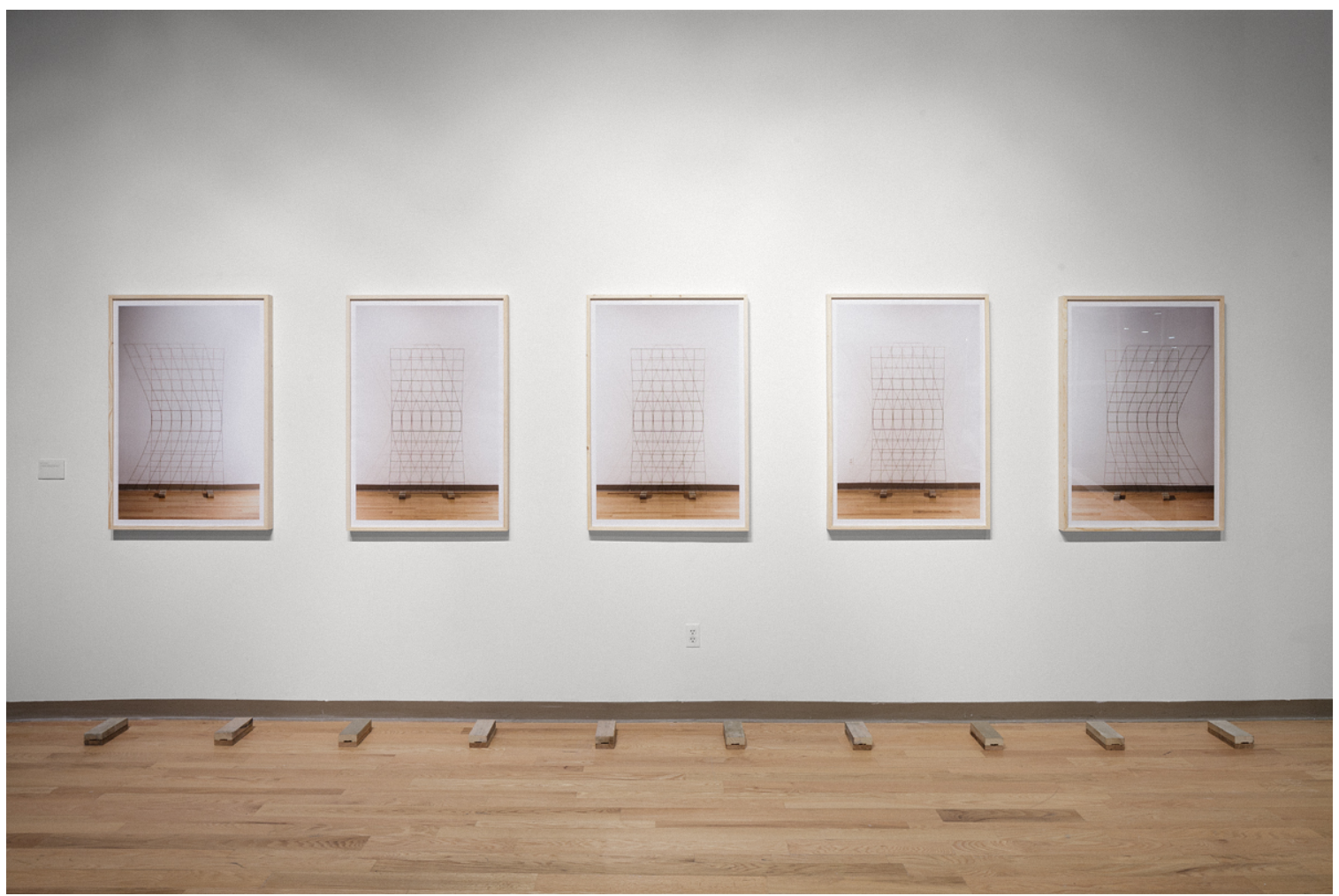

Figure 16. Model \#: 737624 (5)

Five Archival Pigment Prints on Epson Premium Luster Photo Paper, Steel Remesh Sheet 3.5'x7', Found Wood, Kiln-Dried Radiata Pine Softwood Board, OPTIX 0.08-in x 32-in x 44-in Clear Acrylic Sheet 230 " long by 84 " high 2016 


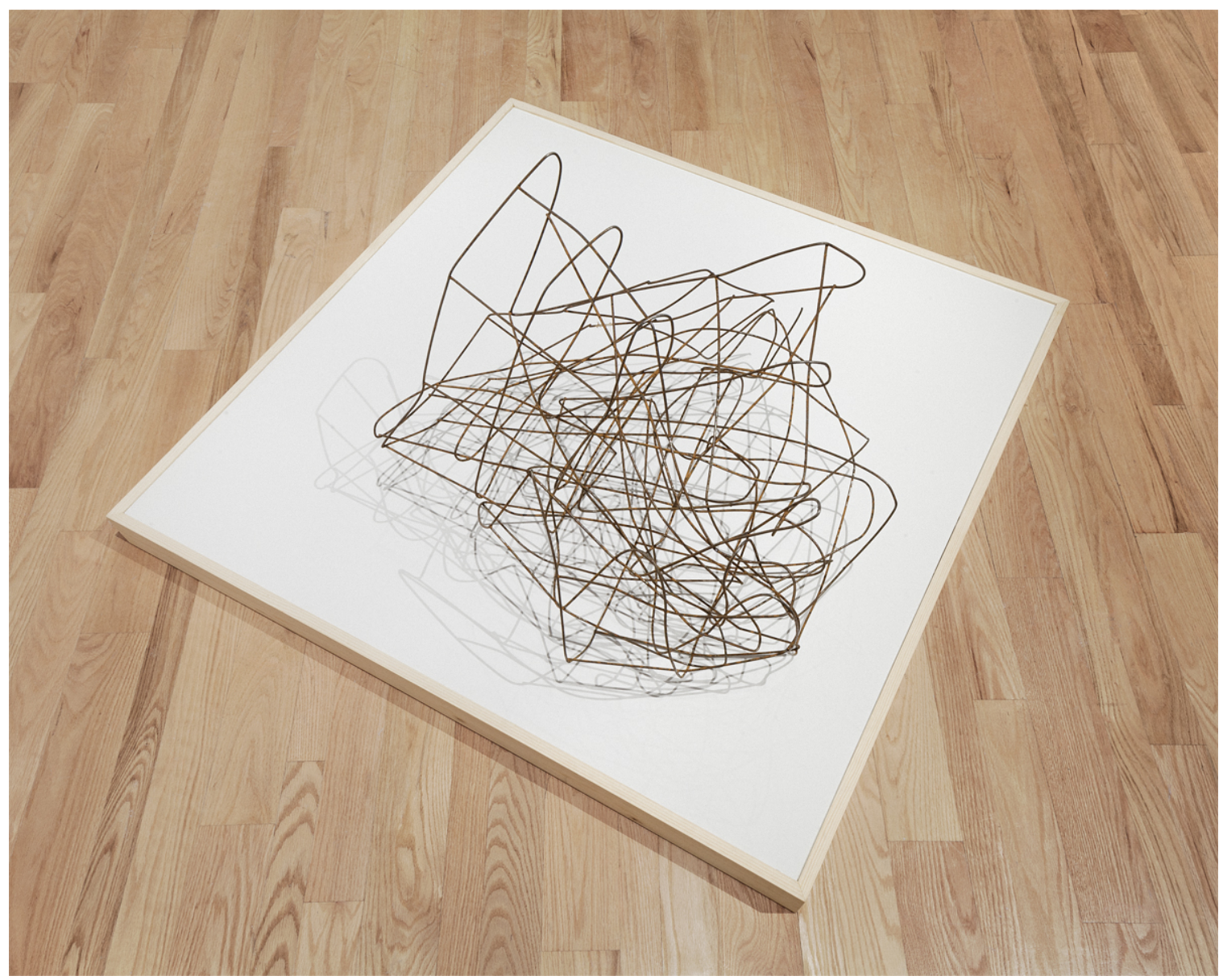

Figure 17. Model \#: 737624 Compressed at 185lbs Steel Remesh Sheet 3.5'x7', Kiln-Dried Radiata Pine Softwood Board, Premium MDF, Valspar Signature White Flat Latex Interior Paint 47 "x47" 2016 


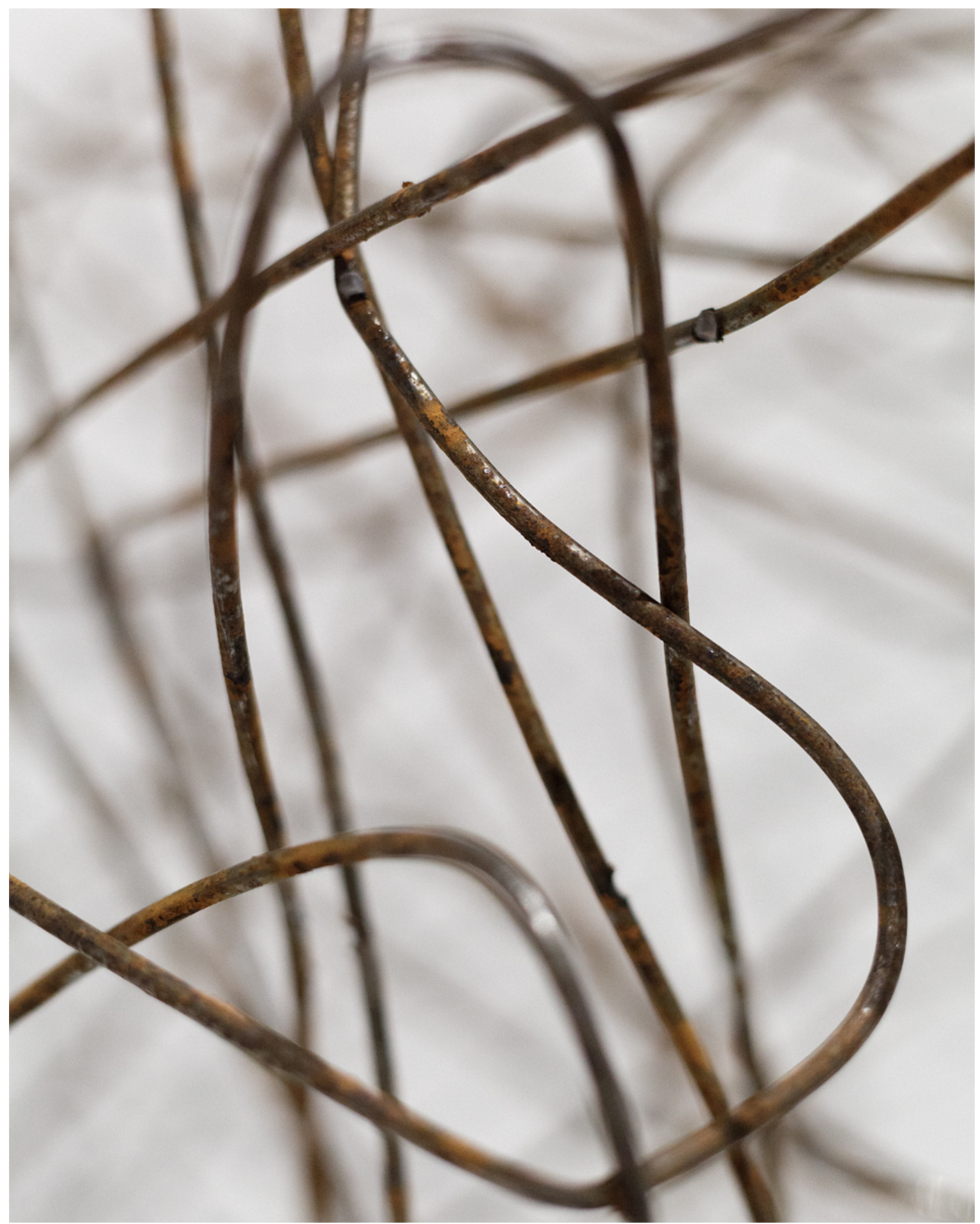

Figure 18. (Detail) Model \#: 737624 Compressed at 185lbs Steel Remesh Sheet 3.5'x7'

2016 


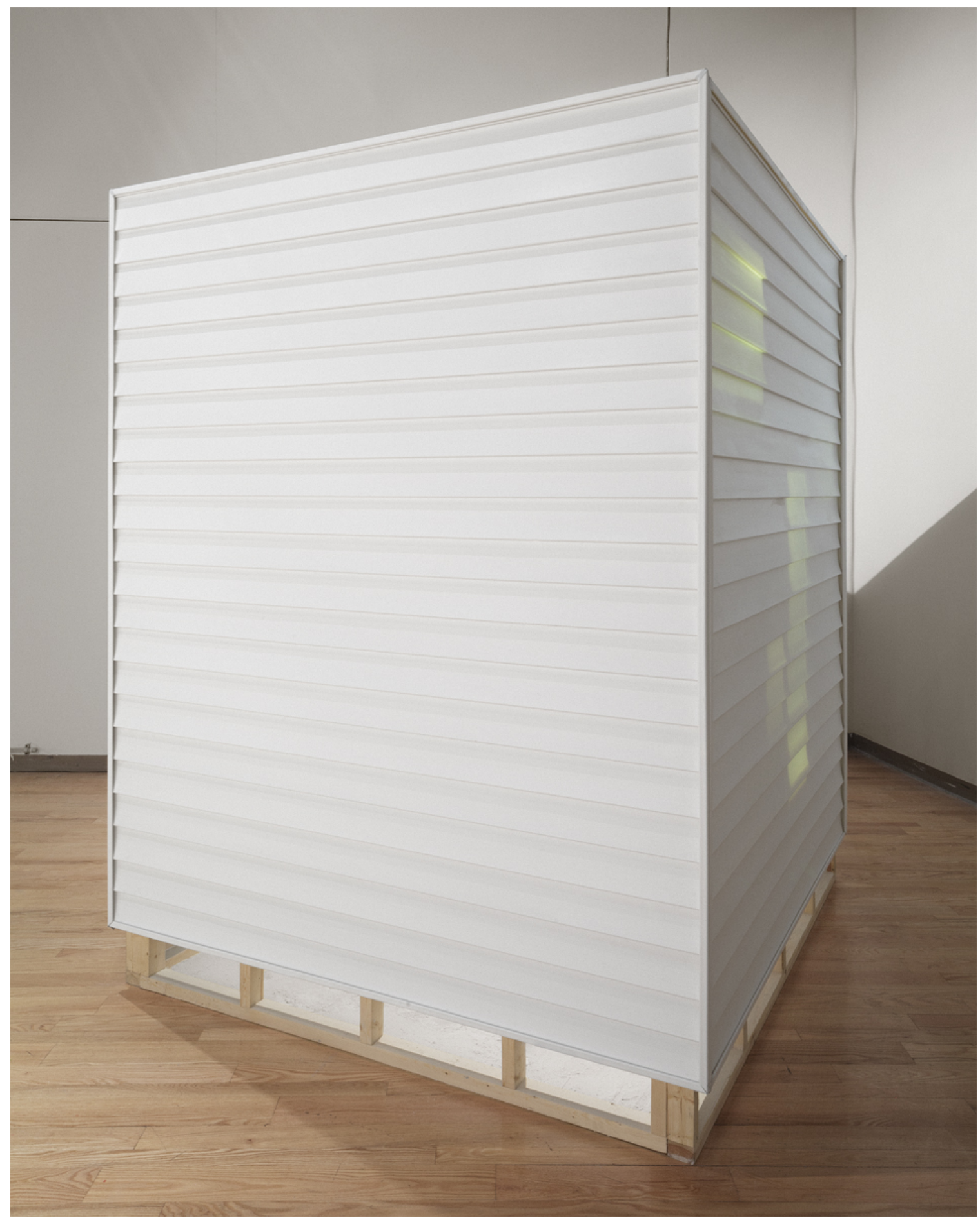

Figure 19. (Exterior) Model \#: 531659A

Georgia-Pacific Vinyl Siding Vision Pro White Wood Grain Double 5 Traditional Vinyl Siding Panel, White J-Channel Vinyl Siding Trim

(Each Panel) 90" tall by 72" wide 2016 


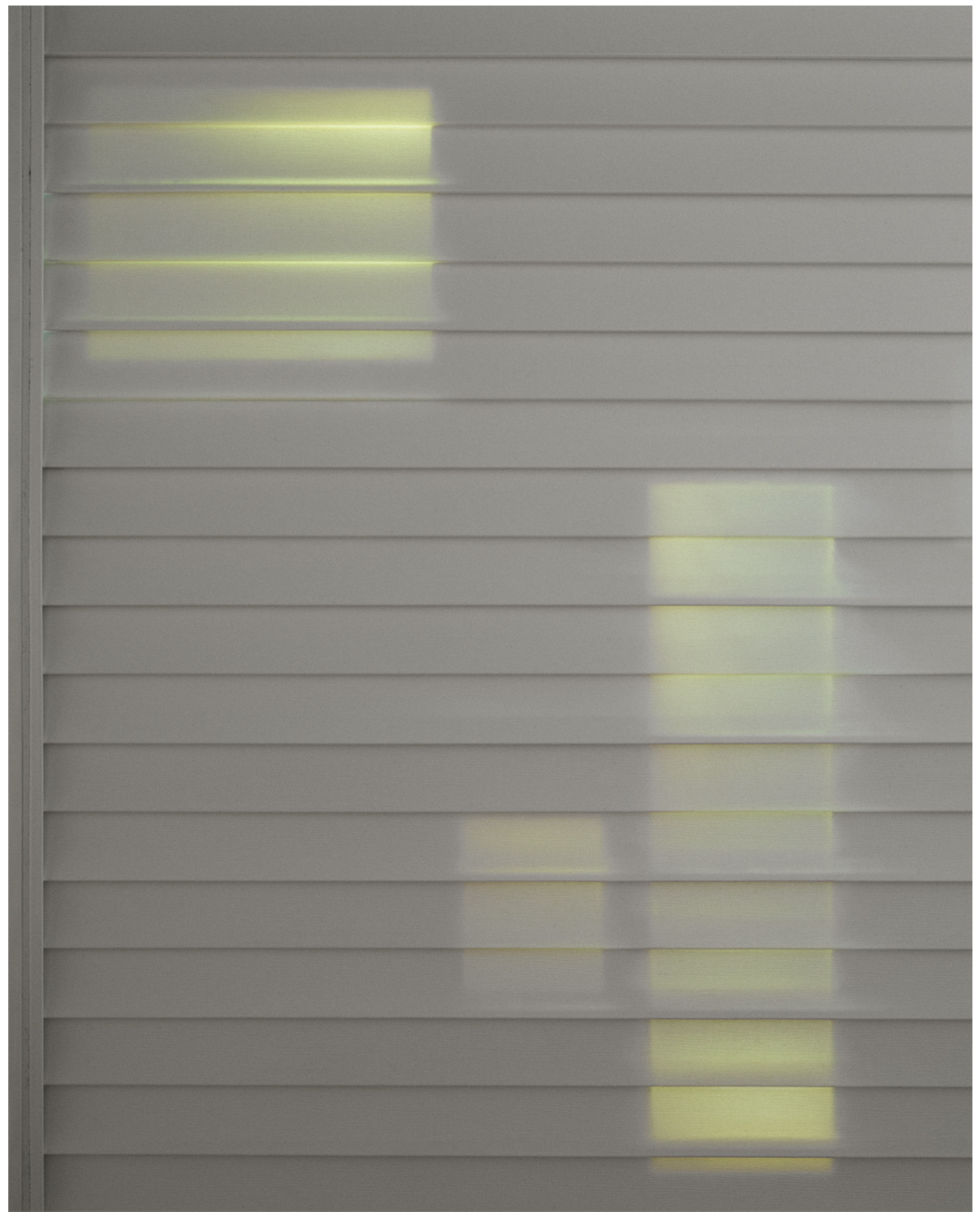

Figure 20. (Exterior) Model \#: 531659 A (Detail)

Georgia-Pacific Vinyl Siding Vision Pro White Wood Grain Double 5 Traditional Vinyl Siding Panel, White J-Channel Vinyl Siding Trim

(Each Panel) 90" tall by 72" wide 2016 


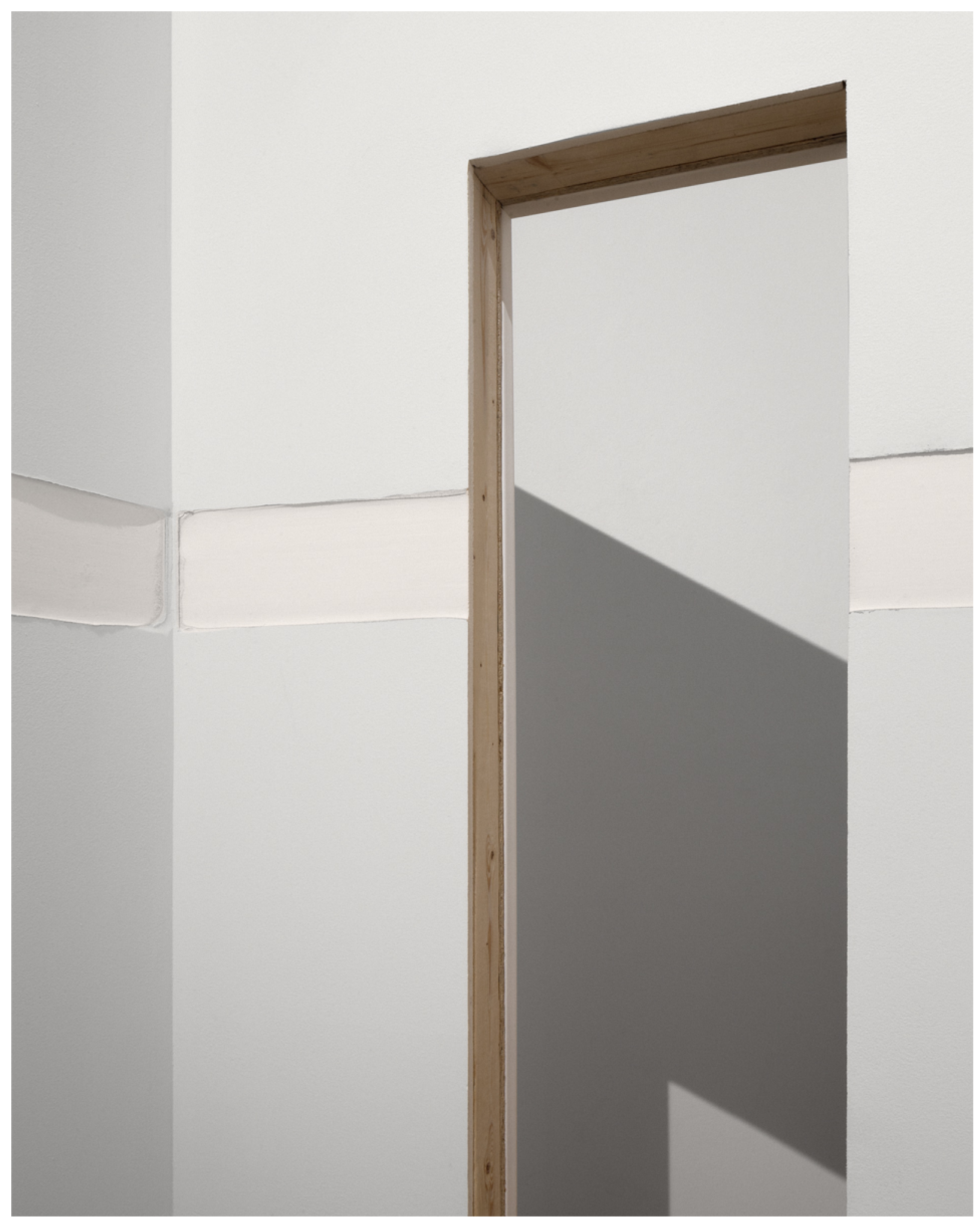

Figure 21. (Interior) Model \#: 1248LLT080000 (6) Reduced

Six Continental Building Products LifeLite Drywall Panels at 4'x8' cut to size, TwentyFive Silicon Carbide Sheets of Sandpaper torn down to 4"x5", 2"x3"Kiln-Dried Whitewood Studs, Grip-Rite 25-lb \#8 x 1.625-in Bugle-Head Black Phosphate Drywall Screw, The Hillman Group 180-Count \#6 x 2-in Flat-Head Ceramic Dual Torque-Drive Deck Screws, Valspar Signature White Flat Latex Interior Paint 2016 


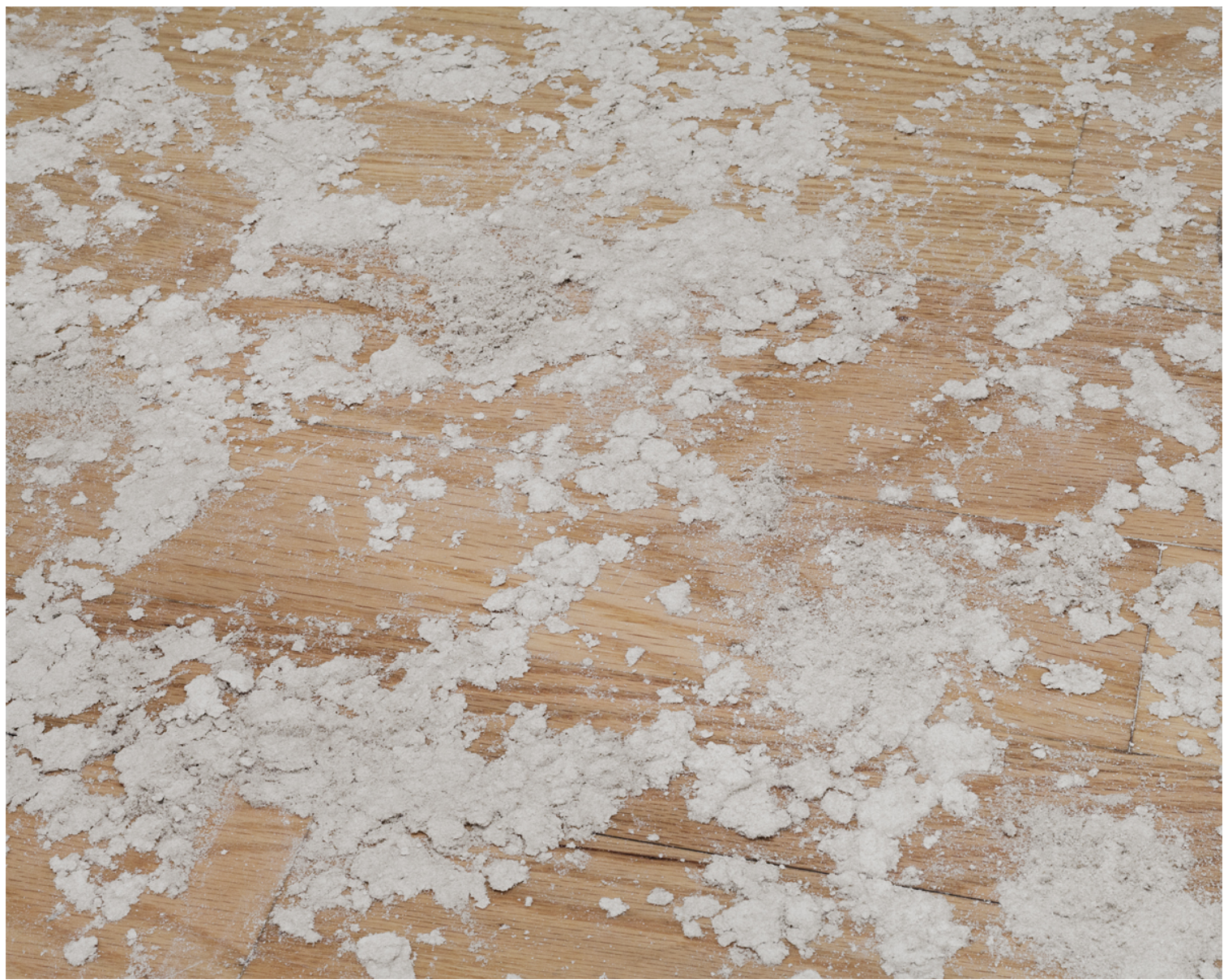

Figure 22. (Interior) Model \#: 1248LLT080000 (6) Reduced (Floor Detail)

Fallen drywall dust and paper particle remnants 2016 


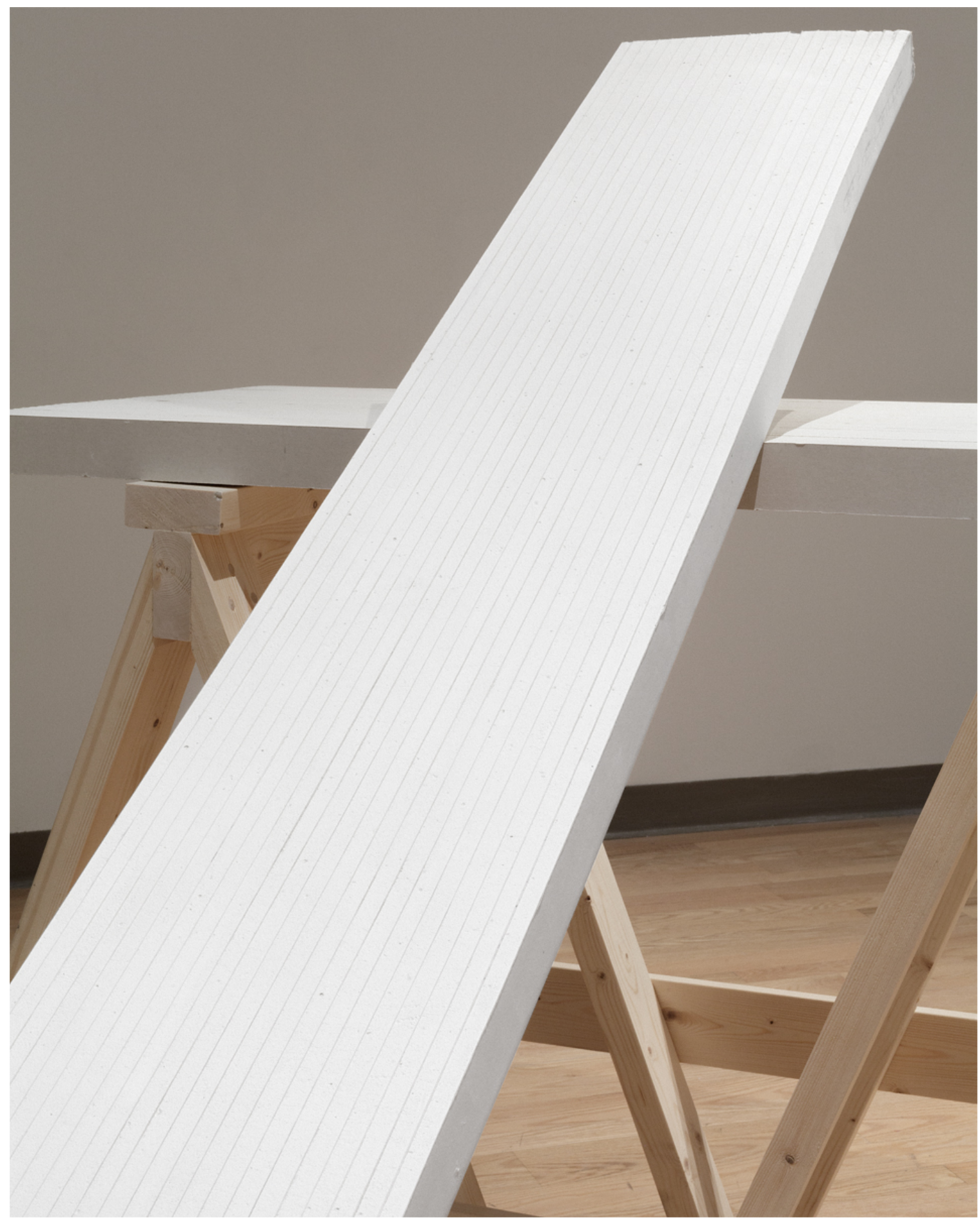

Figure 23. Model \#: 1248LLT080000

Two Continental Building Products LifeLite Drywall Panels at 4'x8', Planed Kiln-Dried Whitewood Stud 2"x4", Madison Mill Poplar Toy Miniature plugs, Mod Podge, Grip-Rite 25-lb \#8 x 1.625-in Bugle-Head Black Phosphate Drywall Screw 2016 


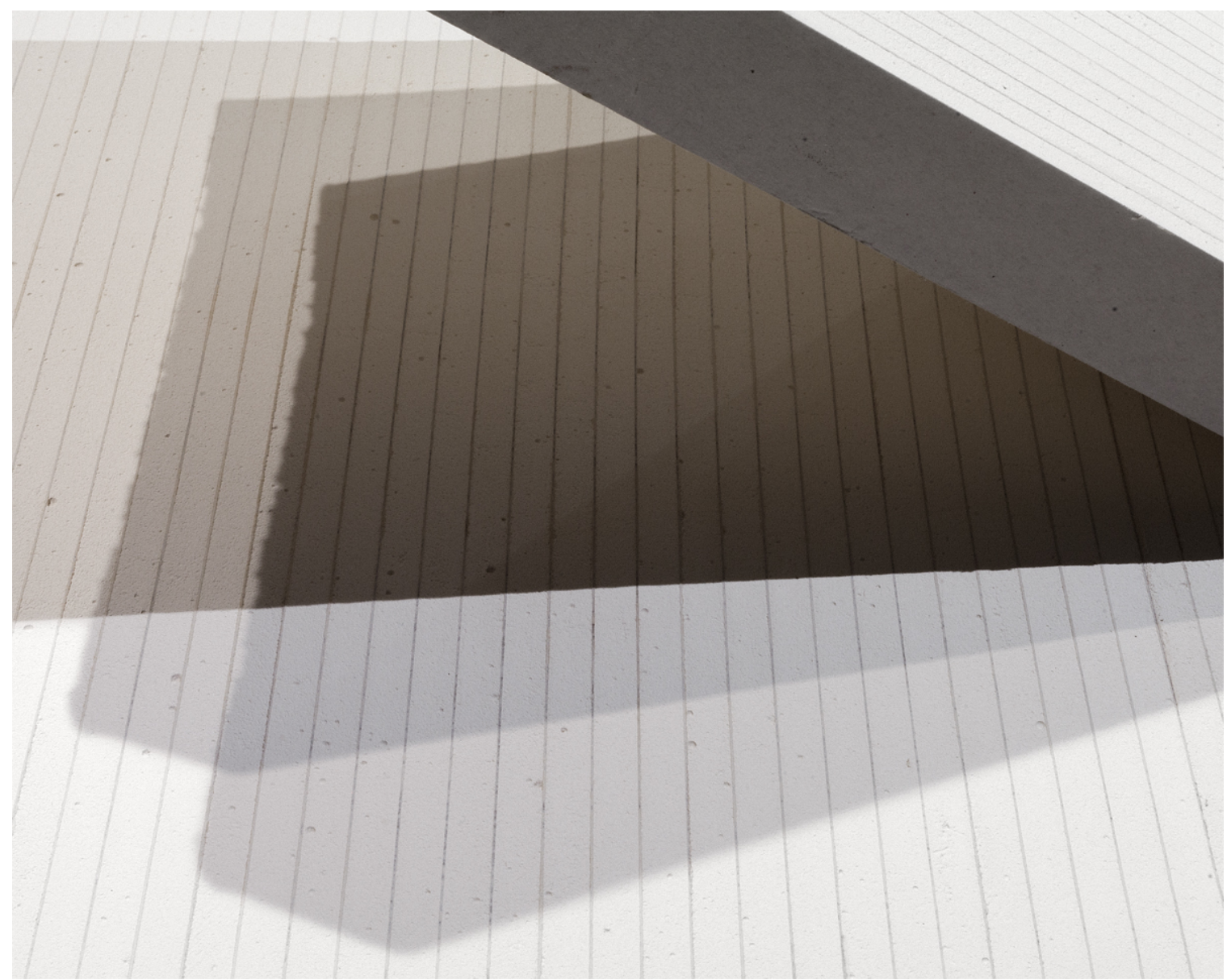

Figure 24. Model \#: 1248LLT080000 (Detail)

Two Continental Building Products LifeLite Drywall Panels at 4'x8', Mod Podge 2016 


\section{Bibliography}

Ades, Dawn, and Marcel Duchamp. Marcel Duchamp. New York, N.Y.: Thames and Hudson, 1999.

Alberro, Alexander. Conceptual Art: A Critical Anthology. Cambridge, Mass.: MIT Press, 1999.

Blazwick, Iwona. Adventures of the Black Square: Abstract Art and Society 1915-2015.

Bru, Sascha. Regarding the Popular Modernism, the Avant-garde, and High and Low Culture. Berlin: De Gruyter, 2012.

Buskirk, Martha. The Contingent Object of Contemporary Art. Cambridge, Mass.: MIT Press, 2003.

Burger, P. Theory of the Avant-Garde. Minneapolis, MN: University of Minnesota Press. 1984

Cabanne, Pierre, and Marcel Duchamp. Dialogues with Marcel Duchamp. New York: Viking Press, 1971.

"Cloud Gate, Tilted Arc | The Point Magazine." The Point Magazine Cloud Gate Tilted Arc Comments. 2012. Accessed April 15, 2016. http://thepointmag.com/2012/criticism/cloud-gate-tilted-arc.

Cohn, Terri. Interview with David Ireland | Art Practical. Art Practical. December 16, 2009. Accessed April 21, 2015.

Davies, Hugh Marlais, and San Diego Art. Blurring the Boundaries: Installation Art, 1969-1996. San Diego, Calif.: Museum of Contemporary Art, San Diego, 1997.

Dickerman, Leah. Dada, New York: National Gallery of Art, Washington, 2005.

Dorment, Richard. "Rachel Whiteread, Gagosian Gallery, London, Review." The Telegraph. Accessed April 02, 2016. http://www.telegraph.co.uk/culture/art/artreviews/9995657/Rachel-Whiteread-Gagosian-Gallery-London-review.html.

Duchamp, Marcel. New York Dada: Duchamp, Man Ray, Picabia ; Städt. Galerie Im Lenbachhaus, München, 15. Dec. 1973-27. Jan. 1974; Kunsthalle Tübingen, 9. March 1974-28. April 1974. München: Prestel, 1973.

Drucker, Johanna. Sweet Dreams: Contemporary Art and Complicity. Chicago: University Of Chicago Press, 2005. 
Editors, Artspace. Book Report: The Four-Hour Art Week? Read Carol Bove's Self-Help Guide for Artists | Artspace. Artspace. March 30, 2015. Accessed April 14, 2015.

"Exhibition - Gladstone Gallery." Accessed April 02, 2016. http://www.gladstonegallery.com/exhibition/1850/press.

Fabozzi, Paul F. Artists, Critics, Context: Readings in and around American Art since 1945. Upper Saddle River, N.J.: Prentice Hall, 2002.

Goldstein, Ann, Anne Rorimer, and Calif Angeles. Reconsidering the Object of Art: 1965-1975. Los Angeles: Museum of Contemporary Art „; 1995.

Greenberg, Clement. The Collected Essays and Criticism: Modernism with a Vengeance, 1957-1969, vol. 4, ed. John O’Brian, Chicago: University of Chicago Press, 1993.

Hamilton, George H. Interview with Marcel Duchamp. BBC Radio Third Programme. New York, January 19, 1959.

Humble, P. N. "Duchamp's Readymades: Art and Anti-Art." The British Journal of Aesthetics 22, no. 1, 1982.

Jones, Amelia. Irrational Modernism a Neurasthenic History of New York Dada. Cambridge, Mass.: MIT Press, 2004.

Joselit, David. Infinite Regress: Marcel Duchamp, 1910-1941. Cambridge, Mass.: MIT Press, 1998.

Lewitt, Sol. Paragraphs on Conceptual Art. Corner-college.com. June 1, 1967. Accessed April 14, 2015.

LeWitt, Sol, and Gary Garrels. Sol LeWitt: A Retrospective. San Francisco, Calif.: San Francisco Museum of Modern Art ; 2000.

Parkinson, Gavin. The Duchamp Book. London: Tate, 2008.

Prager, Phillip Andrew. "Making an Art of Creativity: The Cognitive Science of Duchamp and Dada." Creativity Research Journal 24, no. 4 (October 2012): 266277. Academic Search Complete, EBSCOhost (accessed September 29, 2015).

"Rachel Whiteread: Shedding Life Tate." Rachel Whiteread: Shedding Life, Tate. Accessed April 01, 2016. http://www.tate.org.uk/whats-on/tateliverpool/exhibition/rachel-whiteread-shedding-life.

Roelstraete, Dieter, Simon Starling, and Ill Chicago. Simon Starling: Metamorphology. 
Roth, Moira, and Jonathan Katz. Difference/indifference: Musings on Postmodernism, Marcel Duchamp and John Cage. Amsterdam, The Netherlands: GB Arts International, 1998.

Schwarz, Arturo, and Marcel Duchamp. The Complete Works of Marcel Duchamp. 3rd Rev. and Expanded ed. Vol. II. New York: Delano Greenidge Editions, 1997.

Umland, Anne, and N.Y. York. Dada in the Collection of the Museum of Modern Art. New York: Museum of Modern Art ; 2008.

Weschler, Lawrence. Seeing Is Forgetting the Name of the Thing One Sees: Over Thirty Years of Conversations with Robert Irwin. Expanded ed. Berkeley: University of California Press, 2008. 


\section{Brett Thomas Herron}

b. Pittsburgh 1990

Phone: 412.720.7627 Email: Herron.Brett@gmail.com Website: http://brettherronart.com

\section{Education}

2013-p Master of Fine Art Candidate, WEST VIRGINIA UNIVERSITY, Morgantown, West Virginia

2012 Bachelor of Fine Art in Printmaking, SLIPPERY ROCK UNIVERSITY,

Slippery Rock, Pennsylvania (Minor in Art History)

\section{Teaching Experience}

2013-p Graduate Teaching Assistant, West Virginia University, Morgantown, West Virginia

Advising Professors, Joseph Lupo and Jason Lee

Instructor of Record:

Intro to Intaglio Printmaking

Visual Foundations I

Visual Foundations II

\section{Professional Experience}

2015 Gallery Assistant (Intern) at Jacob Lewis Gallery and Pace Prints Chelsea, New York, NY

Under the direction of Jacob Lewis and Rachel Gladfelter

Worked with artists and gallery directors in choosing various works for exhibitions

Assisted with installation of following exhibitions:

Shepard Fairey: On Our Hands

New Editions: Rina Banerjee, Leonardo Drew, Shepard Fairey, James Turrell Jian-Jun Zhang, Tara Donovan, Dan Walsh, Lucas Samaras

\section{Keith Haring}

Inspected artwork in order to determine the condition

Assist in the preparing, receiving, installing, lighting, wrapping for shipment, local transport, and shipping of artworks on a rotating basis

Maintain the visual appearance of the galleries through repairs, painting, building pedestals, adjusting lights, and fabricating under the guidance of the gallery director and/or visiting artist.

Contribute directly to creative problem solving in the context of installing all artwork including non-traditional artworks.

Chief Preparator, The Art Museum of West Virginia

Constructed 12'x12' movable walls

Installed the entire museum collection in preparation for the inaugural opening 
Curator and Installer Lois Raimondo's solo exhibition "Fragments of Grace" at

West Virginia University Library

2014 Intern, Pace Prints Chelsea, New York, NY

Gallery Director: Rachel Gladfelter

Worked under Master Printmaker Jo Wantanabe at Wantanabe Press

Intern, Jacob Lewis Gallery, New York, NY

Gallery Director: Jacob Lewis

\section{Founding Father of Tautology Collective}

Xia Zhang, Eli Blasko, Lauren Strahl, Eric Charlton, Trevor King

\section{3-p Creator/Director of STUDIO2504, Morgantown, West Virginia}

Sole Preparator

Communicate with artists regarding installation timing and placement of exhibitions

Maintaining online presence through professionally documented gallery images

Coordinate marketing including promotion and interviews with artists

Welcome guests to the gallery, provide information and orientation, assists with inquiries

Exhibiting Artists: Landon Perkins (Tallahassee, Florida) Alberto Careaga (Houston, Texas) Eric D. Charlton (Manhatten, KS), Culture Laboratory Collective (United States and China), Ryder Richards (Mesquite, TX), Lauren Strahl (Las Vegas, NV), Barbara Westman (Pittsburgh, PA), Sharon Massey (Pittsburgh, PA)

Gallery Assistant, Mesaros Galleries, West Virginia University, Morgantown, West Virginia

Worked directly with the curator to ensure the academic year art exhibitions were installed properly on a rotating basis.

Maintained the visual appearance of the galleries.

Set up lighting, applied vinyl, graphics, and signage where applicable, painted, installed and uninstalled artworks.

Assisted with the installation of the following exhibitions:

2016 Conjunction: Projects by West Virginia University Faculty

January - February, 2016, Paul and Laura Mesaros Galleries

2015 Donna Legault

TRANSFORMATIONS: Sonic Horizon, Subtle Territory, Resonant Variations

September - October, 2015, Paul Mesaros Gallery

Dylan Collins

Match Cut

September - October, 2015, Laura Mesaros Gallery 


\section{John Pena}

Daily Geology

October - December, 2015, Laura Mesaros Gallery

Jen Mussari

You Win Some, You Lose Some

October - December, 2015, Paul Mesaros Gallery

How and Nosm

Paper Trail

January - February, 2015, Laura Mesaros Gallery

Assisted with mural painted on the two-story Plevin Lobby wall located in the Art Museum of West Virginia University

\section{Adelaide Paul}

January - February, 2015, Paul Mesaros Gallery

\section{Tugboat Press}

Nature Nurturing

October - December, 2014, Paul Mesaros Gallery

\section{Dennis Ichiyama}

Experiments in Type \& Color

September - October, 2014, Laura Mesaros Gallery

Triangle Poster \& Print Co. with work by Joe Galbreath

Coming Here Soon!

September - October, 2014, Paul Mesaros Gallery

Bachelor of Fine Arts Senior Project Exhibition

April - May, 2014, Laura \& Paul Mesaros Gallery

\section{Silas Spellman}

Liminal Spaces - MFA exhibition

March, 2014, Paul Mesaros Gallery

\section{Kristine Synowka}

MFA exhibition

March, 2014, Paul Mesaros Gallery

Sarah Olsen

Curve to Edge - MFA exhibition

March, 2014, Laura Mesaros Gallery

\section{Andrea Polli}

Breathless - Deem Artist

January - February, 2014, Laura Mesaros Gallery 
DEEM 20: Twenty years of the Deem Distinguished Artist Lecture

January - February, 2014, Paul Mesaros Gallery

2013 Jenny Odell

View Without a Room

October - December, 2013, Laura Mesaros Gallery

Carol Hummel

Telling Yarns

October - December, 2013, Paul Mesaros Gallery

Joshua Dudley Greer

Point Pleasant

September - October, 2013, Paul Mesaros Gallery

Beau Carey and Cedra Wood

Fathom Out

September - October, 2013, Laura Mesaros Gallery

Youxian Zhang

The Essence of Ink- painting on paper

January - February, 2013, Paul Mesaros Gallery

Morgantown, WV

Print Assistant for Visiting Artist Michael Kreuger, West Virginia University,

Morgantown, West Virginia

2012 Intern, Artist Image Resource, Pittsburgh, PA: Print Technician

Print Assistant: Sheppard Fairey, Stefan Hoffmann, Giovanni Forlino

Official Logo Vendor, UMPC Magee Women's Hospital,

Pittsburgh, Pennsylvania

2011 Reneski Replications, Pittsburgh, PA: Worked on artworks for the following artists:

Palden Weinreb: Cascade of the Enshrined

Gonkar Gyatso: Three Realms

The Lacoste Company: La Machine L.12.12.

\section{Solo and Two Person Exhibitions}

2016 SOMEWHAT FAMILIAR, Laura Mesaros Gallery, Morgantown, West Virginia

2014 Unattached Organization, Laura Mesaros Gallery, Morgantown, West Virginia

Installment (with Ryder Richards) STUDIO2504, Morgantown, West Virginia

Digital Distance: An Exploration of Proliferating Internetization (with Eric D, Charlton)

STUDIO2504, Morgantown, West Virginia

2013 Brett Herron: Retroactive Reprography, Shaw Galleries, Pittsburgh Pennsylvania 
2012 Retroactive Reprography, Bachelor of Fine Arts Exhibition, Martha Gault Art Gallery, Slippery Rock University, Slippery Rock, Pennsylvania

Untitled Solo Exhibition, Slippery Rock University, Slippery Rock, Pennsylvania

\section{Selected Group Exhibitions}

2016 Tautology Collective Group Exhibition, Spark Art Space, Syracuse, New York

Confluence: WVU MFA Student Exhibition, Artist Image Resource, Pittsburgh, Pennsylvania

2015 Encountering the Anthropocene: Landscapes of a New Epoch, Tautology Collective, Fairmont State University, Fairmont, West Virginia

LHUCA Warehouse Gallery Exhibition, Tautology Collective, Lubbock, Texas

West Virginia University Student Juried Exhibition, Morgantown, West Virginia.

(Juried by John Pena)

Patent Pending, Charles Adams Gallery, Lubbock, Texas

Confluence: WVU MFA Student Exhibition, Artist Image Resource, Pittsburgh, Pennsylvania

2014 West Virginia University Student Juried Exhibition, Morgantown, West Virginia.

(Juried by Tugboat Printshop)

Bottom Feeders and The Distant Self: Alternative Approaches to Self-Portraiture, Jean Paul Slusser Gallery, University of Michigan School of Art and Design, Ann Arbor, Michigan

Indefinite Spaces Portfolio Exchange, Cross Roads Gallery at the Center of Arts and Culture, University of Notre Dame, South Bend, Indiana

Confluence: WVU MFA Student Exhibition, Artist Image Resource, Pittsburgh, Pennsylvania

WVU MFA Exhibition, Mountainlair, West Virginia University, Morgantown

2013 West Virginia University Student Juried Exhibition, Morgantown, West Virginia. (Juried by Carol Hummel)

Here and Now, National juried printmaking show, Sweetwater Center for the Arts, Sewickley, Pennsylvania

2012 Slippery Rock University Student Exhibition, Bottlebrush Gallery, Harmony, Pennsylvania

Out of Context, The Spinning Plate Gallery, Pittsburgh, Pennsylvania

While You Were Out, Martha Gault Art Gallery, Slippery Rock, Pennsylvania

A.I.R. Crew Show, Artist Image Resource, Pittsburgh, Pennsylvania

2012: End of Time, Regional Juried Show, Pittsburgh Center for the Arts, Pittsburgh, Pennsylvania

SRU Student Juried Exhibition, Martha Gault Art Gallery, Slippery Rock, Pennsylvania Slippery Rock University Student Exhibition, Bottlebrush Gallery, Harmony, Pennsylvania

2011 60x60 Show: Martha Gault Art Gallery, Slippery Rock Pennsylvania

MostoDolce, artwork included in permanent collection, Florence, Italy 
Kaleidoscope Performing Arts Festival: Student Exhibition, Slippery Rock, Pennsylvania

SRU Student Juried Exhibition, Martha Gault Art Gallery, Slippery Rock, Pennsylvania (Juried by Laura Ainsley)

Trash to Treasure Art Competition, Martha Gault Art Gallery, Slippery Rock, Pennsylvania

2010 Kaleidoscope Performing Arts Festival: Student Exhibition, Slippery Rock, Pennsylvania

SRU Student Juried Exhibition, Martha Gault Art Gallery, Slippery Rock, Pennsylvania (Juried by Kate Lydon)

2008 Pittsburgh Technical Institute Visions and Voices, Pittsburgh, Pennsylvania

\section{Visiting Artist and Guest Lectures}

2015 Visiting Artist Talk, Fairmont State University, Fairmont, West Virginia

2014 Visiting Artist Talk and Digital Image Transfer Demonstration, Slippery Rock University, Slippery Rock, Pennsylvania

2013 Retroactive Reprography, SRU Center for Student Research Symposium, Slippery Rock University, Slippery Rock, Pennsylvania

\section{Press/ Reviews / Publications}

2015 Review: October FFAT and APR/TASA Conference, by Vincent Myers, The Bowerbird

2012 Sketchbook Project, Limited Edition, Volume 1: (traveling exhibit)

Hosted by Art House Co-op; Archived in the Brooklyn Art Library Brooklyn, NY;

Austin, TX; Atlanta, GA; Toronto, Canada; Chicago, IL; San Francisco, CA; Portland, OR.

Other Academic Service

2014 Organizer, Visiting Artist Shreepad Joglekar, digital imagery demonstration and presentation, West Virginia University, Morgantown, West Virginia

Organizer, Visiting Artist Jon Whitfill, "Sphere" installation and presentation West Virginia University, Morgantown, West Virginia

Awards and Honors

2013-16 Graduate Teaching Assistantship, West Virginia University, Morgantown, West Virginia

2015 Margaret Tavenner Rajam Art History Endowment Recipient, West Virginia University, Morgantown, West Virginia

Outstanding Student Achievement in Contemporary Sculpture Award Nominee, International Sculpture Center, Hamilton, New Jersey

2012 Charles B. Hamilton Memorial Scholarship, Slippery Rock University, Slippery Rock, Pennsylvania, Based on merit of personal portfolio 
Featured Artist, Slippery Rock University, Slippery Rock, Pennsylvania

2011 Honorable Mention SRU Student Juried Exhibition, Martha Gault Art Gallery, Slippery Rock, Pennsylvania

2008 Third Place Pittsburgh Technical Institute Visions and Voices, Pittsburgh, Pennsylvania

\section{Technical Expertise}

Software: Photoshop, Excel, Word, PowerPoint, Vectorworks (CAD), Google Sketchup

Woodworking: Knowledge of woodworking and carpentry techniques: to include hand and power-tools, table saw, joining, lathe work, drill-press, sanders, staining and finishing. Synthetics: Mold making utilizing plastic, plaster, rubber, silicone, epoxy, acrylic, and resin. Ceramics: working knowledge of electric and gas kiln operations, clay and glaze mixing, slip casting, glazing, high and low fire applications.

\section{Educational Travels}

2015 Southern Graphics Council International, Knoxville, Tennessee

2012 SculptureX Symposium, Cleveland, Ohio

NCECA On The Edge Conference, Seattle, Washington

2011 Renaissance Traditions Research: Rome, Florence, Venice, Sienna, Italy 